\title{
Nutritional approaches for managing obesity-associated metabolic diseases
}

\section{Rachel Botchlett'1,2, Shih-Lung Woo', Mengyang Liu', Ya Pei', Xin Guo1,3, Honggui Li' and Chaodong $\mathrm{Wu}^{1}$}

'Department of Nutrition and Food Science, Texas A\&M University, College Station, USA 2Pinnacle Clinical Research, Live Oak, USA

${ }^{3}$ Baylor College of Medicine, Houston, USA
Correspondence should be addressed to $\mathrm{C} \mathrm{Wu}$

Email

cdwu@tamu.edu

\begin{abstract}
Obesity is an ongoing pandemic and serves as a causal factor of a wide spectrum of metabolic diseases including diabetes, fatty liver disease, and cardiovascular disease. Much evidence has demonstrated that nutrient overload/overnutrition initiates or exacerbates inflammatory responses in tissues/organs involved in the regulation of systemic metabolic homeostasis. This obesity-associated inflammation is usually at a lowgrade and viewed as metabolic inflammation. When it exists continuously, inflammation inappropriately alters metabolic pathways and impairs insulin signaling cascades in peripheral tissues/organs such as adipose tissue, the liver and skeletal muscles, resulting in local fat deposition and insulin resistance and systemic metabolic dysregulation. In addition, inflammatory mediators, e.g., proinflammatory cytokines, and excessive nutrients, e.g., glucose and fatty acids, act together to aggravate local insulin resistance and form a vicious cycle to further disturb the local metabolic pathways and exacerbate systemic metabolic dysregulation. Owing to the critical role of nutrient metabolism in controlling the initiation and progression of inflammation and insulin resistance, nutritional approaches have been implicated as effective tools for managing obesity and obesity-associated metabolic diseases. Based on the mounting evidence generated from both basic and clinical research, nutritional approaches are commonly used for suppressing inflammation, improving insulin sensitivity, and/or decreasing fat deposition. Consequently, the combined effects are responsible for improvement of systemic insulin sensitivity and metabolic homeostasis.
\end{abstract}

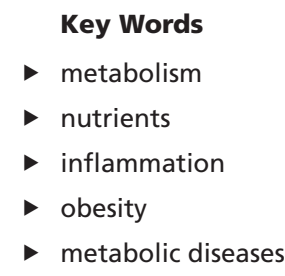

Journal of Endocrinology (2017) 233, R145-R171

\section{Introduction}

With the increasing prevalence of obesity worldwide, there is a drastic rise in the incidence of metabolic diseases. Metabolic syndrome, type 2 diabetes mellitus (T2DM)/insulin resistance, and cardiovascular disease are only a few of the obesity-associated diseases that can cause serious health problems (Wilson et al. 2002, Bhaskaran et al. 2014). Although disturbing physiological metabolism and exacerbating other metabolic problems, these obesity-associated diseases account for upwards of 1.4 billion dollars spent per year in healthcare costs, in the US alone, for the treatment and management of such diseases (Cawley \& Meyerhoefer 2012). Numerous pharmaceuticals are available for treating such disorders; however, it is important for patients/consumers to remember the value and health benefits of food, including both macro- and micronutrients. Nutrients are essential in all aspects of 
health, including the absorption and digestion of food, immune function, brain activity, and exercise ability. Not to mention, proper nutrition for maintaining health and staving off metabolic disease could greatly contribute to lower healthcare costs. Therefore, the purpose of this review is to emphasize the importance of nutrients in metabolism and more importantly, summarize how nutritional approaches can be used to support proper health and treat and/or prevent the onset of metabolic disorders, especially those associated with obesity.

\section{Nutrients and the regulation of metabolic homeostasis}

All nutrients play various yet vital roles in metabolism. This section briefly highlights the physiological significance of macro- and micronutrients. Discussions include current dietary recommendations, primary metabolic pathways and/or functions in which each nutrient is involved, and examples of major foods that are known to contribute to obesity and/or metabolic diseases or shown to benefit metabolism and support health. Although not a nutrient, gut microbiota is discussed given its importance in regulating metabolic homeostasis.

\section{Carbohydrates}

Carbohydrates $(\mathrm{CHO})$ are the primary energy source throughout the body, with multiple tissues and cell types solely depending on CHOs for metabolic needs. For this reason the current acceptable macronutrient distribution range (AMDR) and recommended daily allowance (RDA) for CHOs are $45-65 \%$ of total daily calories and $130 \mathrm{~g} / \mathrm{day}$, respectively (dietary reference intakes (DRIs), United States Department of Agriculture (USDA)). These values are suggested for males and females of all age groups.

After digestion of dietary CHOs, the resulting monosaccharides (mainly glucose) are converted to energy using three major metabolic pathways: glycolysis, the Krebs cycle, and the electron transport chain. From start to finish, this process accounts for the most efficient breakdown/usage of any macronutrient. Therefore, proper $\mathrm{CHO}$ intake not only ensures that cells' energy requirements are met, but also promotes overall metabolic efficiency. In contrast, inadequate intake and/or overconsumption of $\mathrm{CHOs}$ can result in metabolic complications. For example, long-term $\mathrm{CHO}$ deficiency in healthy/normal weight adults can result in hypoglycemia, muscle atrophy, or ketoacidosis, whereas overconsumption, in addition to causing weight gain and/or obesity if chronically overconsumed, can lead to disruptions in sleep-wake cycles, increased risk for nonalcoholic fatty liver disease (NAFLD) and insulin resistance (Flowers \& Ntambi 2009, He et al. 2015b, NeuschwanderTetri 2013, López-Alarcón et al. 2014).

Although over- or under-consumption of CHOs can be detrimental to metabolism, the type of $\mathrm{CHO}$ ingested can also differentially affect the health. Complex $\mathrm{CHO}$ intake (i.e. starches such as amylose and fibers) is associated with a reduced-risk for metabolic diseases including heart disease, T2DM/insulin resistance, and colon cancer compared to the consumption of primarily simple CHOs (Foster-Powell et al. 2002, Jenkins et al. 2002, Domínguez Coello et al. 2010, Mirrahimi et al. 2013, Argiana et al. 2015, Turati et al. 2014, Sieri et al. 2015). Although still a controversial topic, more research is necessary to further define the relationship between simple CHOs and insulin resistance, and/or the onset of metabolic diseases in normal-weight vs. overweight/obese populations. Overall however, results appear to support that reducing simple $\mathrm{CHO}$ intake, fructose and sucrose for example, and increasing intake of complex CHOs, especially in the long term, is more supportive of and beneficial to health.

\section{Fats}

Unfortunately, when it comes to health and body weight, or more accurately, body image, dietary fats commonly receive a disparaging view. However, fats serve multiple beneficial purposes for health and metabolism. For example, fats provide insulation, drive the absorption of fat-soluble vitamins, serve as primary components in phospholipid bilayers and lipoprotein particles, and provide a long-term energy source when needed. Thus, adequate fat intake is vital for metabolism. No RDA for dietary fats exists but the current AMDR for males and females aged 19 years and older is $20-35 \%$ of daily caloric intake (DRIs, USDA). Also included with the adult AMDR is a suggested intake of linoleic acid at $12-17 \mathrm{~g} /$ day and $\alpha$-linolenic acid at $1.1-1.6 \mathrm{~g} /$ day, both of which are essential fatty acids and thus, cannot be synthesized innately but only obtained through the diet.

High-fat diets (HFD; daily caloric intake that exceeds body requirements) are indeed detrimental to health as they can be a potent contributor to lipid accumulation throughout the body and thus, can lead to weight gain relatively quickly (Sampey et al. 2011, Senthil Kumar et al. 2014, Roseno et al. 2015). However, more imperative to health and metabolism is the

Published by Bioscientifica Ltd 
well-documented association between long-term HFD and the generation of inflammation. For example, it is well established that feeding a saturated fatty acid-enriched HFD to mice causes inflammation in various tissues and organs including the adipose tissue (Xu et al. 2003, Huo et al. 2010), the liver (Cai et al. 2005, Woo et al. 2014, Guo et al. 2016), small intestine (Guo et al. 2013, Botchlett et al. 2016), and even the brain (Zhang et al. 2008, Tang et al. 2015). Significantly, chronic HFD-induced inflammation is now considered as a major factor in the onset of many metabolic disorders including obesity, T2DM, cardiovascular disease and some forms of cancer (Hotamisligil 2006, Terzić et al. 2010, Egger 2012). Furthermore, HFD is known to alter the expression of genes involved in metabolic signaling and thus, impair normal metabolic function throughout the body (Choi et al. 2013, Banin et al. 2014).

Although both overconsumption of total calories and dietary fats can be major driving forces in weight gain/obesity, the type of fat consumed can have significant effects on metabolism and/or the generation of inflammation as well. Numerous studies have indeed provided evidence to support the pro-inflammatory role of saturated fats, compared to unsaturated fats (Milanski et al. 2009, Teng et al. 2014), and have demonstrated mechanisms of how saturated fats are linked to metabolic diseases. Although intake of unsaturated fats is recommended over saturated (DRIs, USDA), overconsumption of unsaturated fats can also negatively affect health (Azrad et al. 2013). Nonetheless, adequate intake of unsaturated fats, i.e. within the AMDR, is shown to be less inflammatory and more beneficial to health compared to that of saturated fats.

\section{Proteins}

Dietary proteins/amino acids are only metabolized for energetic needs under extreme conditions, so they primarily benefit health/metabolism in other ways. They provide structure and rigidity to cells, and are necessary for the growth of muscle, bone, and skin, participate in secondary messenger signaling cascades, drive major metabolic pathways such as the Krebs cycle, and play important roles in the metabolism of other macronutrients. As such the current AMDR and RDA for dietary proteins for average adults are $10-35 \%$ and 46-56 g/day, respectively (DRIs, USDA).

Of the twenty essential amino acids, arginine, citrulline and leucine are among the most vital for preventing obesity and/or obesity-related metabolic diseases. For example, beneficial impacts of L-arginine supplementation include increasing energy expenditure favoring reduced growth of white adipose tissue (WAT) (McKnight et al. 2010) whereas dietary L-leucine and L-alanine supplementation reveal similar acute effects on preventing HFD-induced obesity likely by acutely influencing satiety (Freudenberg et al. 2013). Citrulline is shown to play an important role as a marker for the onset of diet-induced obesity (Sailer $e t$ al. 2013) and more recently, exerts a counteractive effect on aging and excess weight-induced metabolic and inflammatory effects in WAT (Joffin et al. 2015). Increased intake of dietary leucine shows significant effects on preventing diet-induced obesity and modulating insulin signaling and glucose homeostasis within muscles (Layman \& Walker 2006, Zhang et al. 2007). Interestingly however, leucine supplementation has the opposite effect when given to already obese rats. Furthermore, obese mice display additional fat accumulation within WAT after supplementation of leucine (Zampieri et al. 2014). Consistently, White and coworkers demonstrated that obese rats display higher levels of circulating branchedchained amino acids (BCAA; leucine, isoleucine, and valine) compared with lean control rats. Furthermore, feeding obese rats an isonitrogenous and isocaloric diet in which all three BCAAs were reduced by $45 \%$ lowers circulating BCAA to levels observed in control diet-fed lean rats and improves skeletal muscle insulin sensitivity. These results suggest a detrimental role of BCAA in obesity and insulin resistance (White et al. 2016). A recent study by Zhenyukh and coworkers also suggest that high levels of BCAA could contribute to the pro-inflammatory and oxidative status (Zhenyukh et al. 2017), thereby exerting a deleterious effect. However, there is also evidence suggesting that higher BCAA levels do not have a causal effect on insulin resistance whereas increased insulin resistance appears to increase the circulating fasting BCAA levels (Mahendran et al. 2017). Interestingly, a recent prospective study demonstrates that putting individuals with type 2 diabetes and NAFLD on diets high in protein (either animal or plant) increases postprandial levels of BCAA and significantly reduces liver fat independently of body weight, and reduces markers of insulin resistance and hepatic necroinflammation. These results validate the beneficial effects of BCAA on diabetes complicated with NAFLD, which is opposite to a detrimental role of BCAA in insulin resistance. Regardless of the controversy, proper intake of amino acids, in particular arginine, citrulline, and leucine, can greatly maintain health and seemingly prevent the onset of obesity and obesity-related metabolic diseases.

Published by Bioscientifica Ltd 


\section{Micronutrients}

Although only needed in trace amounts compared to macronutrients, micronutrients are nonetheless vital to metabolism and crucial in maintaining health. The overall group of micronutrients includes all vitamins and minerals, and can therefore be characterized by the varying functions associated with each subgroup. For example, there are electrolytes (sodium, potassium and chloride), antioxidant micronutrients (selenium, vitamins A, C and E), enzyme cofactors (calcium, manganese, copper and molybdenum), and micronutrients that aid in nutrient absorption and/or metabolism (chromium, vitamins A, D and $\mathrm{E}$ ). With such a wide array of abilities, micronutrients are active in relatively all metabolic pathways/processes including insulin signaling, lipid metabolism, cell differentiation, and the immune response.

Given the obesity epidemic, there is a significant body of literature addressing the relationships between obesity and micronutrients. For example, obesity is shown to be associated with reduced absorption of copper, iron, zinc, and significantly lower the levels of circulating potassium and magnesium (Lukaski et al. 2001, Mariosa et al. 2008, Sonnweber et al. 2012, Suliburska et al. 2013, Zaakouk et al. 2016). Considering this, deficiencies in any one or combination of micronutrients can greatly contribute to impaired metabolism and likely be detrimental to health. As such, the USDA provides a recommend daily intake for most vitamins and minerals (DRIs, USDA). However, there is also research suggesting that high circulating levels of selenium are associated with increased risk of diabetes independent of obesity (Lu et al. 2016). A similar study also indicates that serum vitamin $\mathrm{D}$ concentrations are not associated with the risk of the incidence of insulin resistance in Swiss adults (Marques-Vidal et al. 2015). In adults with moderate obesity, vitamin D status also appears to be unrelated to insulin resistance (Al Masri et al. 2017). In contrast, in the presence of vitamin D deficiency, supplementation of vitamin $\mathrm{D}$ for 6 months generates beneficial effects on glycemic control in type 2 diabetic patients with coronary artery disease (Farrokhian et al. 2017), suggesting the importance of vitamin D in managing metabolic diseases. Regardless, to date, most randomized intervention trials of micronutrient supplements have failed to show an improvement in meaningful clinical biomarkers, such as improved antioxidant status or benefits to vascular or non-vascular endpoints (Woodside et al. 2005). These negative findings, however, should not be considered as evidence to downplay the importance of micronutrients in disease prevention and health promotion. Instead, it indicates the complexity of micronutrients in the context of battling obesity (Woodside et al. 2005), and suggests the necessity of conducting more well-designed, placebocontrolled, and randomized studies in various groups with considerations of age, gender, degree of obesity and ethnicity as biological variables (García et al. 2009, Astrup \& Bugel 2010).

\section{Diet composition}

Although energy density is a critical determinant of nutritional consequences, diet composition appears to be more important in terms of generating profound impact on health. Because of this, a significant amount of studies have examined the effects of healthy diets on metabolic health. In an early isocaloric feeding trial addressing the effects of optimal diets after replacing saturated fats with a diet rich in $\mathrm{CHO}$, protein, or MUFA on blood pressure, Appel and coworkers demonstrated that each of the three diets lowers blood pressure compared with the baseline. Interestingly, partial replacement of $\mathrm{CHO}$ with either protein or MUFA further lowers blood pressure and reduces cardiovascular risk (Appel et al. 2005). A similar trial by Furtado and coworkers also demonstrated that healthy diets that emphasize $\mathrm{CHO}$, protein, or unsaturated fat reduce plasma total and lipoprotein apo B compared with a typical high-saturated fat diet (Furtado et al. 2008). Interestingly, compared with both the $\mathrm{CHO}$ diet and unsaturated fat diet, the protein diet generates the most favorable apo B-containing lipoprotein profile and the lowest plasma total apo B concentrations while reducing plasm levels of triglycerides. A recent trial by Gadgil and coworkers further demonstrated that a diet that partially replaces $\mathrm{CHO}$ with unsaturated fat may improve the insulin sensitivity in a population at risk for cardiovascular disease (Gadgil et al. 2013). Clearly, these randomized trials provide convincing evidence supporting the importance of diet composition in managing metabolic diseases.

\section{Microbiota}

Distinct microbial populations span relatively every part of the human body, including the lungs, nasal passages, vagina, and intestine, and all play their own unique role in maintaining health (Cho \& Blaser 2012). The intestinal microbial community is especially vital to metabolic homeostasis as it participates in nutrient absorption and maintaining the health of the intestinal tract. Specifically,

Published by Bioscientifica Ltd 
intestinal microbiota aid in the production of bioactive compounds and some essential nutrients and metabolites and, arguably their most beneficial role within the intestinal environment, generate short-chain fatty acids (SCFA) (Natarajan \& Pluznick 2015). Although pathogenic bacteria are also present, within normal/healthy hosts diseased/inflammatory states are efficiently regulated and do not negatively alter metabolism.

However, alterations within the microbial community have been implicated in the onset of diet-induced metabolic disorders (Cani et al. 2008, Turnbaugh et al. 2008, Turnbaugh \& Gordon 2009, Suez et al. 2014). Specifically, changes to the normally-occurring gut bacteria are associated with reduced metabolite and/ or peptide production, impaired nutrient absorption, diminished SCFA production, and a proinflammatory state (Cani et al. 2008, Samuel et al. 2008, Ding et al. 2010, Ridaura et al. 2013, Heinritz et al. 2016). Several studies have even indicated that HFD-induced dysbiosis promotes intestinal inflammation that precedes obesity and other metabolic diseases (Bleau et al. 2015, Ding et al. 2010). Thus, it seems alterations to healthy microbial populations can both contribute to and be a result of dietinduced obesity and/or a variety of metabolic diseases. Maintaining a healthy flora is therefore essential in treating and/or staving off such disease states. Indeed, many studies have now demonstrated positive effects from a variety of therapeutics or interventions to combat obesity, diabetes, and others (He et al., Sáez-Lara et al. 2016).

\section{Nutrients, epigenetics, and genetics}

The interplays among nutrients, epigenetics, and genetics have been increasingly studied by many researchers, and are detailed by numerous reviews. Additionally, nutrients or nutrient metabolism can be significantly influenced by genetic factors; although nutrients, per se, have limited roles in altering genetics. Now, it is convincing that nutrients, e.g., nutrients that alter one carbon metabolism, are capable of altering epigenetics to influence the status of health and/or diseases. Indeed, various nutritional approaches are shown to act through, at least in part, modulating epigenetics to bring about beneficial effects, in particular anti-cancer effects (Bishop \& Ferguson 2015). Unlike anti-cancer approaches, there are relatively fewer nutritional approaches that may be used for managing obesity and related metabolic diseases. However, it would be of particular importance in targeting maternal nutrition to reduce the incidence of future offspring obesity.

\section{Pathology of metabolic dysfunction}

Many factors can contribute to impaired local and/or systemic metabolic signaling and in turn, augment the onset of metabolic diseases. This section briefly focuses on the pathology of three primary dysfunctions related to diet-induced obesity. Tissue specific pathologies as well as nutritional interventions to reduce their onset are discussed in subsequent sections. Also, the highlights of nutrition and metabolic dysfunction are summarized in Fig. 1 (see text for detail).

\section{Inflammation/inflammatory responses}

Inflammation is the principal response of the body invoked to deal with injuries and infections. As an acute or short-term adaptive response, inflammation is a crucial component of tissue repair and vital for maintaining cell viability and function. However, long-term consequences of prolonged inflammation are often associated with metabolic disorders, such as insulin resistance, fatty liver disease, T2DM, atherosclerosis and some cancers (Wellen \& Hotamisligil 2003, Zimmermann et al. 2011). Substantial evidence now links obesity with inflammation (Emilsson et al. 2008, Hardy et al. 2011). Unlike acute inflammation, which is usually localized to the site of injury (Warren et al. 2010), obesity-associated inflammation is a low-grade, chronic state (Neels \& Olefsky 2006). Furthermore, inflammation in obesity is a systemic progression that involves the activation of several inflammatory pathways, and the subsequent generation of proinflammatory cytokines, which can contribute to the dysfunction of multiple organ/organ systems (Ouchi et al. 2010, Lumeng \& Saltiel 2011).

Many factors, including diet, play a role in promoting the inflammatory processes. Excess intake of overall or saturated fat and calories for example can activate inflammatory pathways in cells by nutrient-sensing and cytokine signaling mechanisms (Arkan et al. 2005), both of which occur by the stimulation of cell surface receptors including toll-like receptors (TLRs), and/or cytokine receptors such as intracellular pathogen sensing NODlike receptors. Furthermore, these pathways can converge and activate other pro-inflammatory pathways including the mitogen activated protein kinase (MAPK), c-jun $\mathrm{N}$-terminal kinase (JNK), extracellular regulated kinase (ERK), P38 MAPK, the inhibitor $\mathrm{\kappa B}$ kinase (IKK), and protein kinase C (PKC) pathways (Mogensen 2009, Saxena \& Yeretssian 2014). After stimulation of such pathways,

Published by Bioscientifica Ltd 


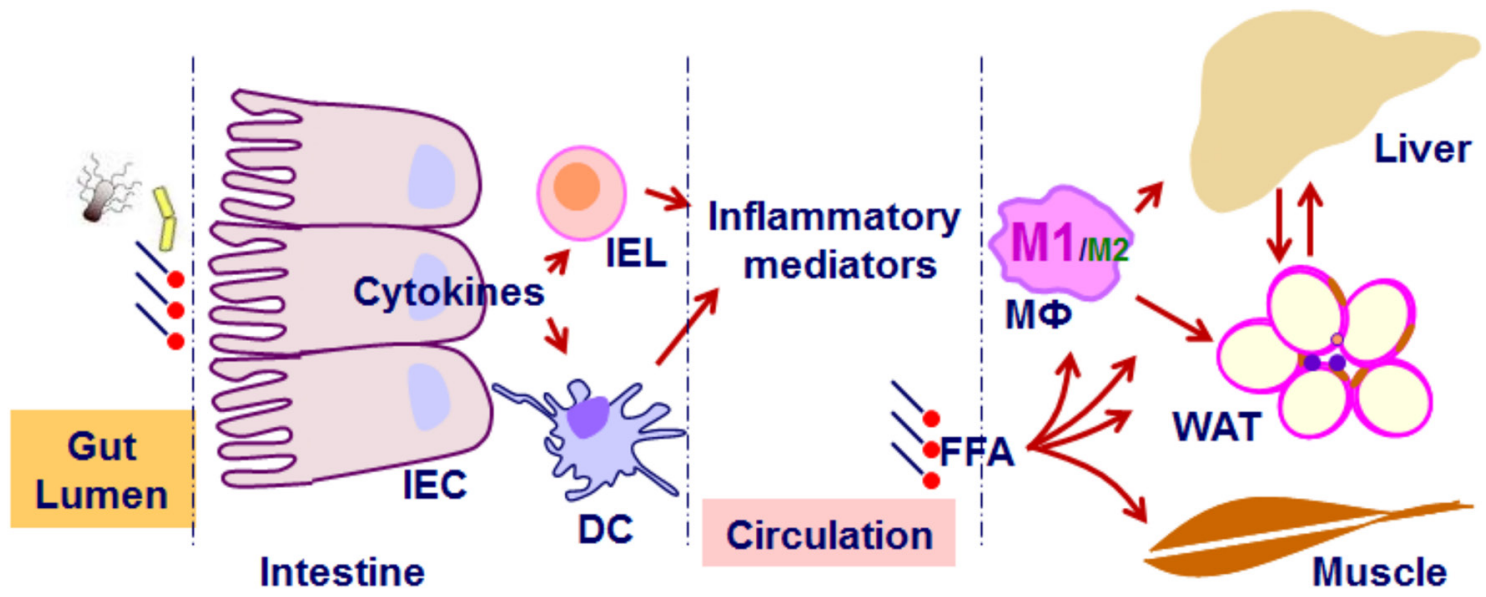

Figure 1

Obesity, inflammation and metabolic dysregulation. During obesity, nutrient overload initiates or exacerbates inflammation in the intestine, adipose tissue and liver. Inflammation, in turn, impairs functions of the liver, adipose tissue, and skeletal muscle to critically contribute to the development of insulin resistance and metabolic dysregulation via working with or without excessive free fatty acids (in particular saturated fatty acids). The interactions between nutrients and host cells e.g., intestinal cells and adipocytes, also generate factors that exert profound actions the brain to alter feeding behaviors, the dysregulation of which contributes significantly to positive energy balance (not depicted). IEC, intestine epithelial cells; IEL, intestine epithelial lymphocytes; DC, dendritic cells; FFA, free fatty acids, and M1/M2, macrophage (M $\Phi)$ polarization.

activated transcription factors including nuclear factor kappa beta (NFkB) can further direct the inflammatory response by binding target gene promoters in the nucleus and in turn lead to the translation of inflammatory cytokine and chemokine genes to activate or enhance the immune responses (Fan et al. 2005).

\section{Fat deposition}

As discussed above, intake of dietary fats is vital to overall health and normal functioning of many metabolic pathways. Following intake, digestion and absorption of dietary fats, triglycerides are formed within the small intestine, packaged into lipoprotein particles, and transported to the liver. During this process triglycerides can be hydrolyzed and converted into glycerol and free fatty acids (FFAs). This is necessary for FFAs to enter adipocytes, be re-esterified into triglycerides, and stored. This overall process is the primary pathway for fat deposition in the adipose tissue and continues as dietary fats are consumed.

When caloric intake chronically exceeds the body's requirements however, fat deposition can be amplified (Speakman 2004). In some cases, excess intake of any one macronutrient can also result in such consequences (Ambrosini et al. 2012, Hörnell et al. 2013, Moslehi et al. 2015, Carreiro et al. 2016). It seems that multiple mechanisms exist for how overnutrition stimulates this process. For example, many studies have reported increased expressions of genes involved in the fat deposition and/or decreased expressions of genes that regulate beta oxidation following overnutrition (Hudgins et al. 2000, Guo et al. 2016). Overnutrition with an HFD is a particularly common cause of weight gain/ obesity as it is shown to contribute to both subcutaneous and visceral WAT deposition (Kubant et al. 2015). In addition, HFD feeding is associated with morphological changes in the intestine, including an increased number and length of villi (Sukhotnik et al. 2004, Dailey 2014), which ultimately increases the efficiency of fat absorption and assimilation into the body (Tchernof \& Després 2013). The combination of enlarged WAT and increased intestinal fat absorption culminates in HFDinduced obesity, which is correlated with abnormal lipid metabolism and dyslipidemia, increased oxidative stress and inflammation, increased intestinal permeability, and a decrease in systemic insulin sensitivity (Huo et al. 2010, Kim et al. 2012, Guo et al. 2013, Botchlett et al. 2016).

\section{Insulin resistance}

Insulin resistance is a pathophysiological condition in which physiological levels of insulin do not adequately produce an insulin response in insulin-sensitive target tissues including adipose, skeletal muscle, and the liver (Fig. 1). One of the major molecular mechanisms underlying insulin resistance is the defects in the insulin signaling pathway (Morino et al. 2006). For example,

Published by Bioscientifica Ltd. 
impaired/altered activation of a member of the family of insulin receptor substrates (IRS), specifically IRS-1, can greatly contribute to systemic insulin resistance. Inflammation/proinflammatory cytokines are widely known to interfere with the insulin signaling pathway, including suppression/interference of IRS-1 and IRS-2 (White 2003). Given that diet-induced inflammation can promote the expression and release of multiple inflammatory stimuli, it is now highly implicated in reduced insulin action/insulin resistance (Hirosumi et al. 2002, Hotamisligil 2006).

HFDs, in particular, interfere with several sites in the insulin signaling cascade. For example, HFD reduces insulin receptor (IR) and IRS1/2 expression and/or phosphorylation (Liu et al. 2015), impairs the phosphorylation of PI3K (Zierath et al. 1997), and decreases the translocation of the glucose transporter GLUT4 to the cell membrane (Zierath et al. 1997). HFD feeding also directly contributes to insulin resistance in the adipose tissue through adipocyte hypertrophy. One major consequence when adipocytes become overly enlarged is increased secretion of FFAs. Excess FFAs enter the bloodstream and accumulate in various tissues causing steatosis and systemic insulin resistance. For example, increased FFAs impair the insulin signal in muscle (Kim et al. 2002) and markedly stimulate hepatic gluconeogenesis (Chu et al. 2002), which contribute to increased glucose production and an exacerbated hyperglycemic phenotype. Moreover, excess FFAs are toxic to pancreatic beta cells and can cause reduced insulin production (Shimabukuro et al. 1998). HFD can also directly impair lipid metabolism. Specifically, it leads to reduced lipolysis through inhibition of $5^{\prime}$ AMPactivated protein kinase (Barroso et al. 2011) and increased lipid accumulation via increased expression of fatty acid synthase (FAS) and acetyl-CoA carboxylase (ACC) (Guo et al. 2016), all of which can intensify systemic insulin resistance.

\section{Nutritional approaches for suppression of obesity-association inflammation}

Over the recent decades, as the rates of health disparities and metabolic diseases have increased, researchers have investigated the mechanisms underlying the onset of such conditions. It is now relatively well understood that inflammation is a primary causal factor in many diseases, especially those associated with diet/overnutrition, such as obesity. This section will discuss dietary interventions/ nutrients that prevent and/or regulate inflammation specifically within the adipose tissue (Fig. 2), liver (Fig. 3), and intestine (Fig. 4).

\section{Suppression of adipose tissue inflammation}

Under normal conditions, the adipose tissue responds to insulin properly, which includes inhibition of lipolysis and stimulation of glucose uptake and fat deposition. However, pathological states such as diet-induced obesity, cause excessive tissue expansion and dysfunction, leading to insulin resistance and subsequently, increased lipolysis and generation of FFA. In such states, several proinflammatory pathways including JNK, IKK, NFkB, cyclic AMP-responsive element-binding protein $\mathrm{H}$ (CREBH) are triggered, and ROS are generated (Hotamisligil \& Erbay 2008, Huo et al. 2010). Adipocytes in turn secret cytokines in response to enhanced inflammatory signaling, including tumor necrosis factor alpha (TNF $\alpha$ ), interleukin (IL)-1, IL-6, resistin, and monocyte chemoattractant protein-1 (MCP-1). In addition to adipocytes, the adipose tissue also contains numerous immune cells that are activated during proinflammatory/ disease states. For example, in obesity there is increased macrophage infiltration into the adipose tissue and more importantly, a phenotypic switch from anti-inflammatory, M2, to proinflammatory, M1, macrophages. Newly recruited macrophages, together with the adipose tissue proinflammatory resident macrophages, promote further secretion of cytokines and chemokines. This low-degree, chronic inflammation in the adipose tissue plays an important role in the development of systemic insulin resistance, and can lead to metabolic and cardiovascular diseases (Berg \& Scherer 2005).

One proposed dietary intervention for reducing obesity-associated adipose tissue inflammation is intake of long-chain (LC) omega-3 (n-3) polyunsaturated fatty acids (PUFAs), such as eicosapentaenoic acid (EPA) and docosahexaenoic acid (DHA). First, they are precursors to resolvins and protectins, endogenous chemical compounds for the withdrawal of proinflammatory cytokines (Bannenberg et al. 2005). Secondly, LC n-3 PUFAs can bind G protein-coupled receptor 120 (GPR120) and repress macrophage-induced inflammation and promote insulin sensitivity (Oh et al. 2010). Thirdly, EPA and DHA give rise to series 3 prostaglandins that are less inflammatory compared to series 2, normally derived from arachidonic acid (Calder 2010). In fact, in $d b / d b$ mice, a rodent model for diet-induced diabetes, mice

Published by Bioscientifica Ltd. 


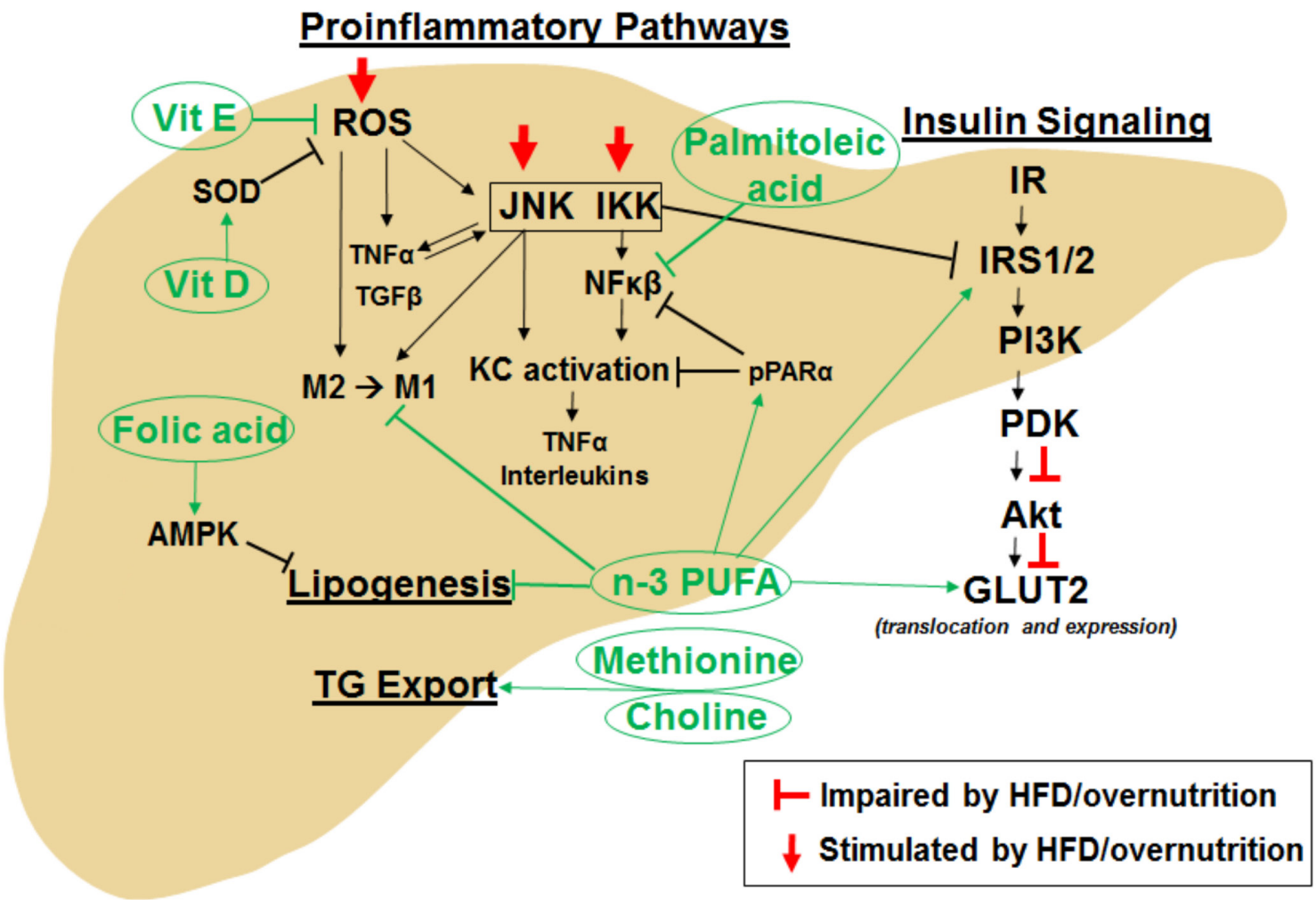

\section{Figure 2}

Nutritional approaches for managing obesity-associated metabolic impairments in the liver. AMPK, AMP-activated protein kinase; GLUT2, glucose transporter 2; IKK, Iк $\beta$ kinases; IR, insulin receptor; IRS1/2, insulin receptor substrate 1/2; JNK, c Jun N-terminal kinase; KC, Kupffer cell; n-3 PUFA, omega-3 polyunsaturated fatty acid; $\mathrm{NF} \kappa \beta$, nuclear factor kappa beta; $\mathrm{M} 1$, proinflammatory macrophage; $\mathrm{M} 2$, anti-inflammatory macrophage; PDK, phosphoinositide-dependent kinase; PI3K, phosphoinositide 3-kinase; PPAR $\alpha$, peroxisome proliferator-activated receptor alpha; ROS, reactive oxygen species; SOD, superoxide dismutase; TG, triglyceride; TGF $\beta$, transforming growth factor beta; TNF $\alpha$, tumor necrosis factor alpha; Vit $D$, vitain $D$; Vit $E$, vitamin $\mathrm{E}$.

supplemented with n-3 PUFA showed significantly reduced macrophage infiltration into the adipose tissue and reduced JNK phosphorylation compared with HFD alone, or HFD supplemented with n-6 PUFA (Todoric et al. 2006). In addition to regulating systemic inflammation, n-3 LC PUFAs can also prevent hyperplasia and hypertrophy in the adipose tissue, and induce adiponectin secretion and mitochondrial biogenesis in adipocytes (Kopecky et al. 2009).

Although the results from basic nutrition research are promising and encouraging, there is also increasing evidence validating the efficacy of nutritional approaches for suppressing the adipose tissue inflammation. As indicated by the results from a human trial by Itariu and coworkers, treatment of severely obese nondiabetic patients with LC n-3 PUFAs for 8 weeks decreased proinflammatory biomarkers in both visceral and subcutaneous adipose tissues, as well as circulating levels of IL-6 (Itariu et al. 2012). This anti-inflammatory effect of LC n-3 PUFAs, however, was not associated with a decrease in body weight and improvement of insulin sensitivity. A similar trial showed that treatment of insulin-resistant, nondiabetic subjects with n-3 fatty acids for 12 weeks decreased adipose tissue macrophages, increased capillaries, and reduced MCP-1 expression (Spencer et al. 2013). Consistently, treatment with n-3 fatty acids did not significantly alter body weight and systemic insulin sensitivity. Although the effects of supplementation of $\mathrm{n}-3$ fatty acids on reducing body weight remained controversial (see 'Adipose tissue and reduction of adiposity' section), there appears to be no doubt that n-3 fatty acids are capable of reducing inflammation, including that in the adipose tissue. Additional to n-3 fatty acids, monounsaturated fatty acids (MUFAs) also exhibit anti-inflammatory effects. As supporting evidence, a parallel controlled-feeding trial in abdominally overweight subjects revealed that consumption of a MUFA diet for 8 weeks caused a more anti-inflammatory profile in the adipose tissue comparing to consumption of a saturated fatty acid diet (van Dijk et al. 2009). Unlike PUFA, MUFA diets appear to be more promising in improving insulin 


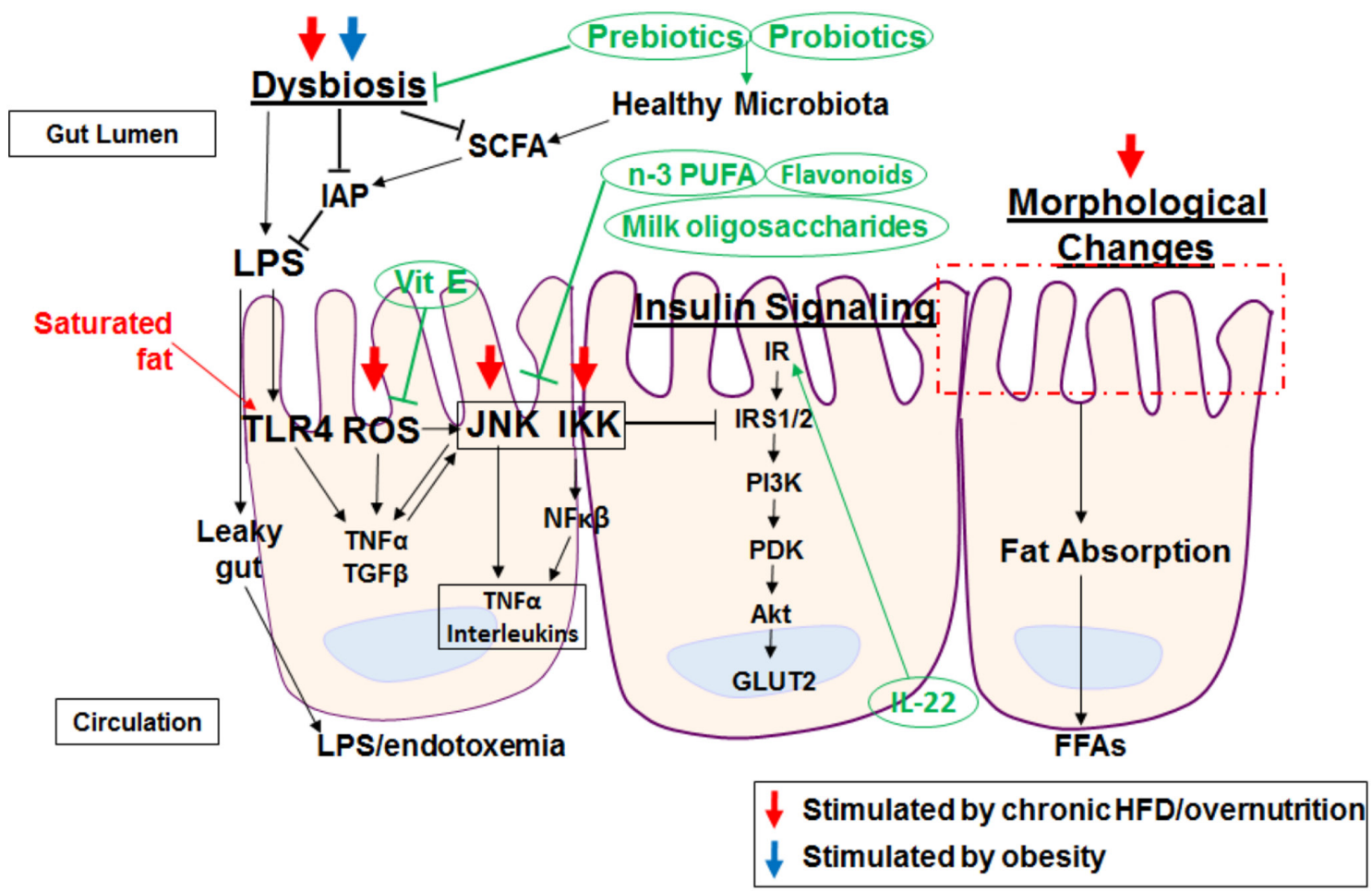

Figure 3

Nutritional approaches for managing obesity-associated metabolic impairments in the small intestine. AMPK, AMP-activated protein kinase; FFAs, free fatty acids; GLUT4, glucose transporter 4; IKK, IK $\beta$ kinases; IR, insulin receptor; IRS1/2, insulin receptor substrate 1/2; JNK, c Jun N-terminal kinase; M1, proinflammatory macrophage; $\mathrm{M} 2$, anti-inflammatory macrophage; MCP-1, monocyte chemoattractant protein 1; n-3 PUFA, omega-3 polyunsaturated fatty acid; $\mathrm{NF \kappa} \beta$, nuclear factor kappa beta; PDK, phosphoinositide-dependent kinase; PI3K, phosphoinositide 3-kinase; pPAR $\alpha$, peroxisome proliferatoractivated receptor alpha; ROS, reactive oxygen species; SIRT1, sirtuin 1; SOD, superoxide dismutase; TG, triglyceride; TGF $\beta$, transforming growth factor beta; TNF $\alpha$, tumor necrosis factor alpha.

sensitivity (see 'Nutritional approaches for insulin sensitization' section).

Another dietary component with anti-inflammatory actions is polyphenolic compounds that inhibit NFKB and MAPK inflammatory pathways, and activate the AMPK pathway in the adipose tissue. Curcumin, derived from thizomes of the plant Curcuma longa (turmeric), is a major polyphenol investigated for this purpose. In fact, in vitro studies have demonstrated that curcumin inhibits hydrogen peroxide $\left(\mathrm{H}_{2} \mathrm{O}_{2}\right)$-induced oxidative damage and reduces apoptotic death in human bone marrow-derived mesenchymal stem cells (Yagi et al. 2013). Specifically, it appears that curcumin inhibits the generation of ROS via alteration of the PI3K/AKT/ mTOR signaling pathway and subsequent inhibition of FOXO1 translocation to the nucleus (Han et al. 2012). In endothelial cells, curcumin protects from oxidative injury through blocking Notch signaling that in turn reduces cell apoptosis (Yang et al. 2013). Further, within macrophages curcumin is reported to decrease expressions of NFKB and
IL-1 $\beta$ (Du et al. 2013). Systemically, in vivo studies using rats have shown significantly decreased TNF- $\alpha$ and IL- 6 levels after treatment with $50 \mathrm{mg} / \mathrm{kg}$ per day of curcumin (Alghasham et al. 2013). Similarly, Kant and coworkers showed that treatment with $0.3 \%(400 \mu \mathrm{L})$ curcumin not only reduced inflammatory cytokines, but also promoted wound contraction and increased expressions of antiinflammatory molecules such as IL-10 and anti-oxidant enzymes such as superoxide dismutase, catalase and GPx (Kant et al. 2014). Given the premise of anti-oxidants in suppressing proinflammatory responses, a significant amount of human trials have been performed to examine the effects of mixed fruit and vegetable supplements on inflammatory biomarkers. As summarized by the review article by Esfahan and coworkers, most studies have validated the beneficial effects of daily consumption of fruits and vegetables on suppressing inflammation (Esfahani et al. 2011). However, most studies also have limitations related to the diversity of studies and study population.
(C) 2017 Society for Endocrinology Printed in Great Britain 


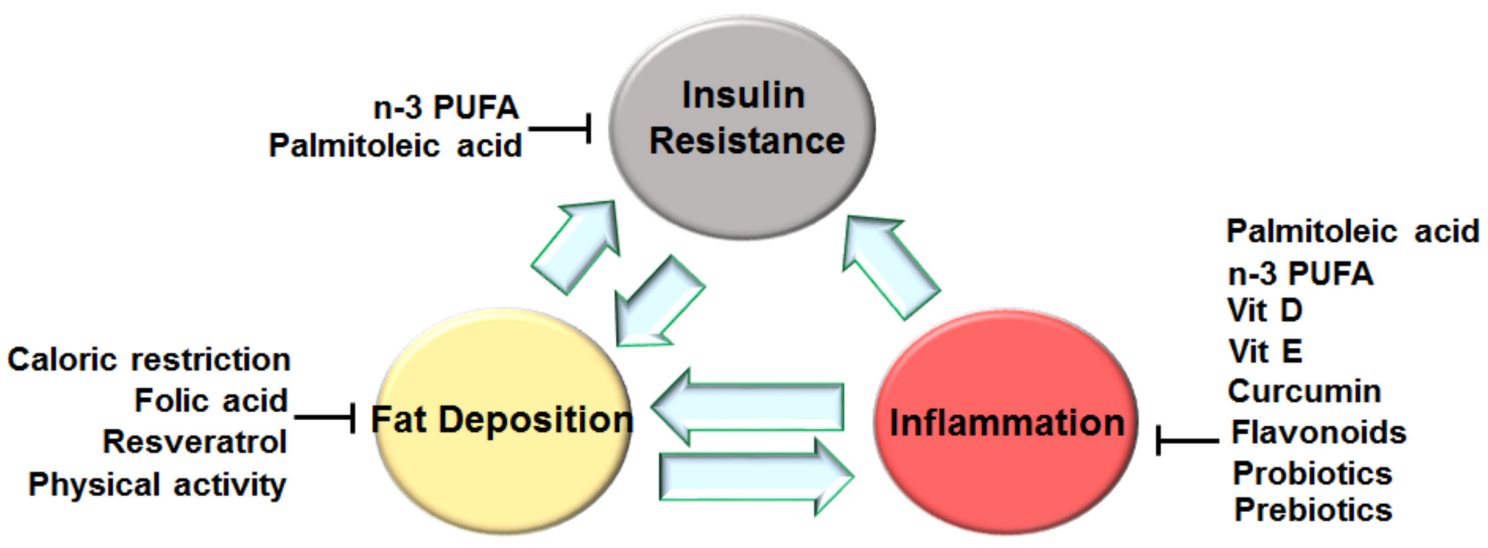

\section{Figure 4}

Summary of nutritional approaches for managing obesity-associated metabolic dysregulation. Most of the currently used approaches are shown to be effective at suppressing inflammation, improving insulin sensitivity, and/or decreasing fat deposition. At the integrative level, the combined effects on key metabolic tissues including the intestine, the liver, adipose tissue and muscle bring about improvement of metabolic dysregulation. In addition, nutritional approaches should be combined with healthy life style, e.g., sufficient physical activity and appropriaste circadian clock rhythms of daily life, to maximize the beneficial effects (not depicted). n-3 PUFA, omega-3 polyunsaturated fatty acid; Vit D, vitamin D; Vit E, vitamin E.

\section{Suppression of liver inflammation}

The liver is a complex organ composed of various cell populations including hepatocytes and Kupffer cells (KCs). During both acute and chronic liver inflammation, activated KCs promote the generation of proinflammatory cytokines via activation of JNK and NFkB signaling pathways. This manifestation of inflammation is especially true with obesity as increased circulating levels of FFAs are well known activators of KCs. Chronic overnutrition/ HFD intake, and subsequent chronic activation of proinflammatory pathways, could also trigger a fibrotic response as the generation of myofibroblasts is triggered to replace damaged/dead hepatocytes. This irreversible damage signifies the onset of declining hepatic function in disease states including obesity.

Many researchers have investigated dietary factors to combat and/or regulate inflammation within the liver. In particular, n-3 PUFAs, palmitoleic acid, and vitamins $\mathrm{E}$ and $\mathrm{D}$ have known beneficial effects. Systemically, intake of n-3 PUFA is associated with reduced circulating proinflammatory markers including CRP, cytokines, proinflammatory eicosanoids, and others (Schwab \& Serhan 2006). Studies using experimental models of liver injury have specifically shown that n-3 PUFAs are able to prevent liver necroinflammatory injury through decreasing liver oxidative stress and DNA damage (González-Périz et al. 2006). In addition, n-3 PUFAs are also known agonists of peroxisome proliferator activated receptor $\alpha$ (PPAR $\alpha)$ (Zúñiga et al. 2011), which is known to inhibit NFkB activity (Huang et al. 2016). Recently, it has been reported that the activation of liver PPAR $\alpha$ by n-3 PUFAs is able to increase the PPAR $\alpha / N F \kappa B$ interaction, thereby reducing the expression of proinflammatory cytokines (Zúñiga et al. 2011). It seems that n-3 PUFAs exert this effect in KCs through activation of GPR120, a putative receptor for $\mathrm{n}-3$ fatty acids (Oh et al. 2010). These effects in turn decrease activation/phosphorylation of JNK and NFkB, as well as stimulate the phenotypic shift from M1 to M2 macrophages, to concomitantly reduce the generation of inflammation.

Palmitoleate, a MUFA, has recently been discovered to exert anti-inflammatory effects in the liver (Guo et al. 2012). For example, palmitoleate serves to reduce the liver inflammatory status in an animal model of HFDinduced insulin resistance seemingly by reducing $\mathrm{NF \kappa B}$ signaling in macrophages (Guo et al. 2012). Similar results have also recently been reported by Souza and coworkers Specifically, palmitoleic acid supplementation in mice resulted in reduced liver proinflammatory cytokine production of IL-1 $\beta$, IL-12, and TNF $\alpha$, all of which was associated with reduced NFkB signaling and decreased TLR4 expression (Souza et al. 2014).

Vitamin E is well known for its anti-inflammatory ability throughout the body. In the liver, vitamin E acts at the propagation phase of lipid peroxidation to donate a hydrogen group, affectively neutralizing the free radical. The vitamin $\mathrm{E}$ itself is then converted to tocopheroxyl radical, which reacts with other peroxyl radicals to form non-radical products. This ability of vitamin $\mathrm{E}$ is especially important in non-alcoholic steatohepatitis (NASH), a condition commonly associated with obesity, where increased levels of oxidative stress within hepatocytes

Published by Bioscientifica Ltd. 
trigger the formation of proinflammatory cytokines such as TNF $\alpha$, TGF $\beta$, and IL-8. In fact, supplementation with vitamin $\mathrm{E}$ in an animal model of NASH significantly reduced NFKB signaling and the expression of markers for cell apoptosis such as Bax and Bcl-2 (Nan et al. 2009). Vitamin D, although most widely known for its role in calcium homeostasis, recently has also been shown to exert anti-inflammatory properties within the liver. For example, vitamin D supplementation in mice resulted in increased expression of antioxidant molecules including glutathione peroxidase and superoxide dismutase (George et al. 2012). Further, vitamin D supplementation in a rodent model for NASH lead to a decrease in the progression of liver inflammation, as shown by an improvement in liver histology (Nakano et al. 2011). This study also reported that phototherapy elevated levels of the active form of vitamin D which contributed to a reduction in hepatocyte apoptosis and reduced gene expressions of several proinflammatory cytokines. Interestingly, vitamin D deficiency is associated with increased TLR4 expression in the liver. Roth and coworkers suggested that this effect is due to a shift in microbiota following vitamin D deficiency, which causes an increase in bacterial translocation and thus, increased endotoxin exposure within the liver (Roth et al. 2012). Unlike animal studies, there are limited human trials studying the effects of dietary interventions on liver inflammation. However, the anti-inflammatory effects generated by nutritional approaches, i.e., PUFAs, MUFAs, and anti-oxidants, may also lead to suppression of liver inflammation in human subjects.

\section{Suppression of intestine inflammation}

Several disease states can lead to the development of inflammation in the small intestine. Physical damage, bacterial, viral or parasitic infections, or severe disorders such as Crohn's disease can all contribute to increased inflammation as the responding immune system involves macrophage recruitment and T-cell activation, both of which stimulate inflammatory cytokine pathways. Much research also implicates obesity in inflammatory cytokine production in the small intestine. Diet-induced models of obesity, particularly HFD feeding studies in rodent models using saturated fats, are especially powerful to induce an obese phenotype relatively quickly. Results from such studies show that chronic HFD feeding directly contributes to the generation of inflammation in the small intestine through increased TLR4 expression (de La Serre et al.
2010), phosphorylation of JNK (Guo et al. 2013) and IKK (Arkan et al. 2005), and mRNA levels of IL-6 and TNF $\alpha$ (Guo et al. 2013). Interestingly, TLR4 and NFKB expressions are also increased after only short-term HFD (Wang et al. 2013). In addition, HFD-induced obesity also seems to indirectly contribute to small intestinal inflammation via changes in the gut microbial composition. Specifically, several mouse studies have demonstrated a shift in the ratio of Firmicutes to Bacteriodetes populations (Turnbaugh et al. 2006, Turnbaugh et al. 2008). This shift leads to increased production of LPS, which generates inflammation locally through stimulation of the TLR4 signaling pathway, and can contribute to systemic inflammation and worsen the obese phenotype (Cani et al. 2008). HFD-induced dysbiosis is also associated with reduced levels of intestinal alkaline phosphatase (IAP) (de La Serre et al. 2010), which normally functions to detoxify LPS. Changes in microbiota could also alter SCFA concentrations which, when lacking, may promote small intestinal inflammation as reviewed by de Besten and coworkers (den Besten et al. 2013). Collectively, these findings indicate that diet-induced obesity contributes to small intestinal inflammation via both direct and indirect mechanisms.

Many adults suffer from intestinal discomfort, whether from minor conditions or diagnosed diseases. Current dietary interventions to reduce intestine inflammation and thus, lessen the pain associated with such conditions include treatment with both macroand micronutrients. For example, in rodent models of colitis and/or in vitro studies investigating antiinflammatory therapeutics milk oligosaccharides, PUFAs, and polyphenolic compounds such as flavonoids are shown to significantly reduce intestinal inflammation (Lara-Villoslada et al. 2006, Vezza et al. 2016). Given this, it is a logic extension to use dietary approaches for protecting against obesity-associated intestinal inflammation. Indeed, there is an ongoing clinical trial in obese and non-obese individuals testing the ability of low-fat dairy yogurt to improve gastrointestinal health and reduce chronic inflammation (ClinicalTrials.gov Identifier: NCT01686204). Regardless of the outcomes, targeting intestinal inflammation to maintain metabolic homeostasis or correct metabolic dysregulation via nutritional approaches is increasingly attracting research attention. Among established anti-inflammatory dietary components, n-3 PUFAs are shown to decrease obesityassociated intestinal inflammation, evidenced by its effects on suppressing Th1/Th17 cells (Monk et al. 2012). In addition to dietary components, pre- and probiotics can
Published by Bioscientifica Ltd 
prevent HFD-induced shifts in the intestinal microbiota (Heo et al. 2016). In fact, following HFD feeding treatment with probiotics can actually return the microbial community to its original pre-diet distribution (Heo et al. 2016). Given the vast diversity of the human microbiome across subjects/patients, a few interventions will certainly not benefit everyone. Thus, continued research is further investigating additional nutritional therapeutics for HFDinduced/obesity-associated inflammation within the intestinal environment.

Over the past several decades, a number of human trials have focused on the efficacy of various dietary components on intestine inflammation and related diseases, in particular inflammatory bowel disease (IBD). However, to date, there are limited trials examining the effects of nutritional approaches for suppressing obesityrelated intestine inflammation. This may be due to the fact that it is a relatively new concept that obesityrelated intestine inflammation precedes and correlates with insulin resistance (Ding et al. 2010, Du et al. 2015). However, it is expected that in the future more trials will specifically address whether and how diets suppress intestine inflammation in the context of preventing or reversing obesity-related metabolic dysregulation.

\section{Nutritional approaches for reducing fat deposition}

In non-diseased physiological states, with balanced nutrient and caloric intake, fat deposition is closely regulated and well-managed within the adipose tissue. However, with abnormal metabolism and/or diseases, such as obesity, fat deposition can become uncontrolled, induce inflammation, and occur outside of adipocytes. This section focuses on nutrient/dietary interventions to prevent against the onset of impaired/abnormal lipid metabolism and fat deposition within the adipose tissue, liver, and intestine (Figs. 2, 3, and 5).

\section{Adipose tissue and reduction of adiposity}

To support proper/healthy fat deposition, it is recommended to consume complex carbohydrates and lean protein, and limit saturated fat intake. In addition, several functional foods are thought to contribute to healthy fat deposition. Curcumin for example, increases the levels of activated AMPK which in turn decreases the ACC activity, which is a master regulator of lipogenesis.
Inactivity of ACC results in elevated carnitine palmitoyl transferase 1 (CPT1) activity and subsequently, increased LC fatty acid $\beta$-oxidation. Curcumin also inhibits the expression of PPAR $\gamma$ and $\mathrm{C} / \mathrm{EBP} \alpha$, which are the key transcription factors involved in adipogenesis and lipogenesis within the adipose tissue. By suppressing the differentiation of pre-adipocytes into adipocytes, curcumin can also suppress the enlargement of adipocytes/adipose tissue and thus, potentially help in staving off weight gain and/or obesity (Aggarwal 2010).

Resveratrol, a non-flavanol polyphenol found in red wine, is another functional food with beneficial abilities in combating diet-induced obesity. Specifically, resveratrol is involved in the downregulation of lipogenesis via increasing levels of SIRT 1 and PPAR $\gamma$ coactivator $1 \alpha$ (PGC1 $\alpha$ ) (Higashida et al. 2013). SIRT 1 represses PPAR $\gamma$ and thus, serves to inhibit adipogenesis and triggers lipolysis in mature fat cells (Picard et al. 2004). PGC1 $\alpha$ helps to regulate mitochondrial biogenesis and oxidative metabolism, which increases rates of $\beta$-oxidation in the adipose tissue and can lead to reduced body fat (Liang \& Ward 2006).

It appears that caloric restriction (CR) is a powerful and effective approach for reducing body weight, as well as adiposity (see 'Caloric restriction' section). Additional to CR, both PUFAs and MUFAs are shown to alter body fat composition or even reduce fat mass. For example, in a small-size human study involving healthy adults, substitution of fish oil for visible fats in a control diet $(52 \%$ carbohydrates, $16 \%$ protein, $32 \%$ fat; polyunsaturated: saturated (P: S 0.2)) for 3 weeks reduced body fat mass (Couet et al. 1997). Similarly, in a trial examining the effects of dietary oils, supplementation with conjugated linoleic acid (CLA), but not safflower oil (SAF) for 36 weeks significantly reduced body mass index and total adipose mass without altering lean mass (Norris et al. 2009). In overweight or obese children, supplementation of CLA also reduced body fatness (Racine et al. 2010). However, there are also many studies that could not support an exact anti-obesity role for $\mathrm{n}-3$ PUFAs in overweight/ obese subjects, which suggest the necessity of conducting more large-scale and long-term clinical trials (Du et al. 2015). Compared with PUFAs, MUFAs appear to be more promising in terms of reducing fat mass. As supporting evidence, the results of a 6-month randomized and controlled trial involving nondiabetic overweight or obese men and women revealed that MUFA diets allowed less body fat regain than did the control diet (Due et al. 2008). More interestingly, consumption of an isocaloric http://joe.endocrinology-journals.org DOI: $10.1530 / J O E-16-0580$
() 2017 Society for Endocrinology Printed in Great Britain
Published by Bioscientifica Ltd 


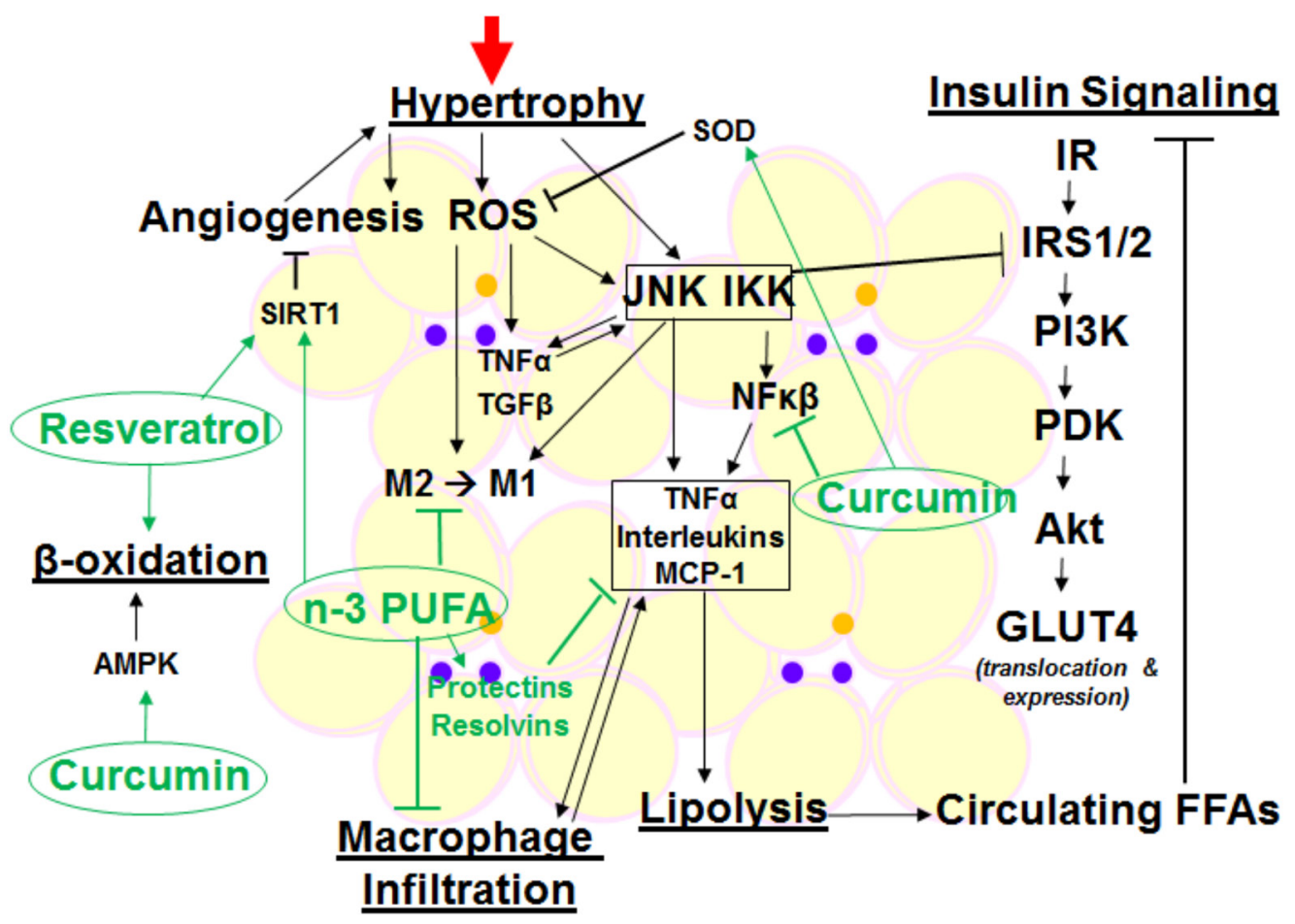

Stimulated by chronic HFD/overnutrition

\section{Figure 5}

Nutritional approaches for managing obesity-associated metabolic impairments in adipose tissue. AMPK, AMP-activated protein kinase; FFAs, free fatty acids; GLUT4, glucose transporter 4; IKK, II $\beta$ kinases; IR, insulin receptor; IRS1/2, insulin receptor substrate 1/2; JNK, c Jun N-terminal kinase; M1, proinflammatory macrophage; M2, anti-inflammatory macrophage; MCP-1, monocyte chemoattractant protein 1 ; n-3 PUFA, omega-3 polyunsaturated fatty acid; $\mathrm{NF \kappa} \beta$, nuclear factor kappa beta; PDK, phosphoinositide-dependent kinase; PI3K, phosphoinositide 3-kinase; pPAR $\alpha$, peroxisome proliferatoractivated receptor alpha; ROS, reactive oxygen species; SIRT1, sirtuin 1; SOD, superoxide dismutase; TG, triglyceride; TGF $\alpha$, transforming growth factor beta; TNF $\alpha$, tumor necrosis factor alpha.

MUFA-rich diet prevented central fat redistribution induced by a CHO-rich diet in insulin-resistant subjects (Paniagua et al. 2007). In future trials, it may be important to examine the anti-obesity effects of mixed diets.

\section{Brown adipose tissue and promotion of thermogenesis}

Brown adipose tissue (BAT) is unique from the more abundant WAT primarily in its ability to generate heat via thermogenesis. Within the mitochondria of BAT, uncoupling protein 1 (UCP1) allows hydrogen ion flux directly from the inner membrane to the matrix, without activating ATP synthase. BAT contains significantly more mitochondria compared to WAT, which equates to more nutrient energy converted to heat, which then elevates glucose metabolism and increases the production of energy. Therefore, more BAT theoretically means more energy expenditure and/or weight loss. However, humans lose a significant amount of BAT as they mature from infants to adults. Nonetheless, nutrients and foods to increase BAT is a popular research focus for reducing and/ or preventing diet-induced obesity.

Some research has indicated that BAT can be activated or stimulated by dietary components, particularly those in spicy foods. For example, non-pungent analogs of capsaicin (capsinoids) are reported to activate BAT in adult humans (Yoneshiro et al. 2012, Yoneshiro et al. 2013). One suggested mechanism is that thermogenesis is increased via stimulation of the transient receptor potential vanilloid receptor (TRPV1) (Szallasi et al. 1999) and upregulation of UCP1 (Yoneshiro et al. 2013). In addition, ingestion of capsinoids increases energy expenditure significantly, even in as short as $30 \mathrm{~min}$ (Saito 2013). Specifically, consumption of $2.56 \mathrm{mg}$ capsaicin per meal can counteract the unfavorable decrease in energy expenditure during negative energy balance and can boost fat oxidation (Janssens et al. 2013). There are many vanilloids with structures similar to capscin, such as piperine found in pepper, gingerols, shogaol, and 6-paradol found in ginger. All of these compounds are

Published by Bioscientifica Ltd 
also shown to act as agonists for TRPV1 and recruit BAT for thermogenesis (Saito 2013). Thus, repeated ingestion of these compounds could potentially contribute to repeated stimulation of BAT thermogenesis in humans. Continued research to investigate other activators of BAT is of significant interest.

The discovery of beige adipocytes led to the consideration of promoting the development of beige adipocytes in WAT (browning) as a new avenue for management of metabolic disease (Bartelt \& Heeren 2014). In addition, a great number of studies have advanced the understanding of the molecular mechanisms underlying browning. To date, however, there is no effective browningbased therapeutic approach for managing obesity and related metabolic diseases. Consistently, Abdullahi and coworkers raised the concern that the notion of browning is supposedly beneficial may be inadequate (Abdullahi \& Jeschke 2016).

\section{Liver and reduction of steatosis}

The liver is a major metabolic organ involved in fat metabolism. Although a major role of the liver under normal/healthy conditions is not to store fat, it is responsible for a significant amount of de novo lipogenesis, including esterification of dietary fatty acids derived from chylomicron remnants, and plasma non-esterified fatty acids (NEFA) derived from adipose tissue lipolysis. Betaoxidation and triglyceride export in the form of verylow density lipoprotein (VLDL) also occur within the liver. Thus, in pathological states, such as overnutrition and/or diet-induced obesity, dysregulation of any of these processes could lead to abnormal fat deposition in the liver. In fact, excessive fat deposition could pose significant physiological consequences that could lead to metabolic diseases such as alcoholic and non-alcoholic fatty liver diseases.

Several nutrients have been found to protect against excessive hepatic fat deposition. These nutrients include methionine, choline, n-3 PUFAs, and folic acid. Both methionine and choline play important roles in the endogenous synthesis of phosphatidylcholine (Corbin \& Zeisel 2012), one of the components of VLDL, and thus, the export of triglycerides from the liver. Indeed, mice fed a methionine and choline-deficient diet (MCD) develop severe hepatic steatosis (Anstee \& Goldin 2006). In fact, MCD diet is so potent that it is now used to fed mice as a model for in vivo/diet-induced liver damage. As discussed in a previous section, one of the primary benefits of $n-3$
PUFAs is its anti-inflammatory ability. However, n-3 PUFAs exert additional effects within the liver. As ligands of PPAR $\alpha$, which is a nuclear receptor for genes involved in $\beta$-oxidation, n-3 PUFAs have been shown to increase hepatic $\beta$-oxidation via upregulation of fatty acid binding protein (FABP) and CPT1 (Bordoni et al. 2006, Jump 2008). In addition, n-3 PUFAs are shown to decrease hepatic lipogenesis by reducing the expression and maturation of sterol regulatory element binding protein-1c (SREBP-1c), thereby downregulating the transcription of hepatic lipogenic genes such as ACC and FAS (Howell et al. 2009, Jump 2008). Lastly, because folic acid is a cofactor in the synthesis of 5-aminoimidazole-4-carboxamide 1- $\beta$-Dribofuranoside (AICAR), which is an activator of AMPK, there is recent evidence suggesting that folic acid may be protective against hepatic steatosis. The likely mechanism seems that folic acid decreases lipogenesis via increasing activation of AMPK (Buettner et al. 2010), which in turn reduces expression and/or activity of ACC. However, further validations are necessary to confirm these effects of folic acid.

Although basic research has generated a huge body of knowledge regarding nutritional regulation of the pathogenesis of steatosis, there are limited trials examining dietary interventions on hepatic fat deposition. Given the beneficial effects of dietary approaches for reducing body weight and adiposity, it is also interesting to examine if the same approaches result in beneficial effects on hepatic steatosis. Indeed, there is an ongoing randomized controlled trial to examine whether consumption of a Mediterranean diet reduce liver fats (Papamiltiadous et al. 2016). There is a hope that more of this type of trials will be performed in near future.

\section{Intestine and improvement of fat metabolic homeostasis}

The digestion and absorption of triglycerides in the intestine is a complex progression involving emulsification, hydrolysis of fatty acid ester bonds, and aqueous dispersion of lipolytic products, and mainly occurs in the proximal jejunum and distal parts of the ileum. The major products of triglyceride digestion, monoglycerides and fatty acids, are absorbed by enterocytes through simple diffusion by using micelles, which delivers the products from within the intestinal lumen to the intestinal microvilli. Once absorbed, products are re-synthesized into triglycerides within the smooth endoplasmic reticulum before excretion into the lymphatics system. This process occurs repeatedly, as dietary fats are consumed, and in healthy http://joe.endocrinology-journals.org DOI: $10.1530 / J O E-16-0580$ (c) 2017 Society for Endocrinology Printed in Great Britain
Published by Bioscientifica Ltd 
individuals does not seem to pose any negative metabolic affects. During the digestion and absorption processes, chylomicrons deliver dietary fats, and thus play a prominent role in fat homeostasis. Due to this, increasing evidence from animal studies has indicated that limiting the rate of intestinal triglyceride synthesis and/or altering chylomicron response could modulate gut hormone secretion, lipid metabolism, and systemic energy balance (Yen et al. 2015).

Following overnutrition however, and particularly overnutrition with fat, research shows altered intestinal morphology including increased height and number of microvilli, jejunal mucosal weight, and total protein content (Dailey 2014). Consequently, these effects culminate not only in increased absorptive surface area but increased efficiency of fatty acid absorption within the intestine. Although it is unclear if this effect alone impairs metabolism or stimulates pro-inflammatory mechanisms within the intestine, it does show that overnutrition with HFD significantly impacts the small intestine and subsequently, can contribute to increased circulating fatty acids/triglycerides. As discussed previously, this in turn can lead to increased fat deposition (i.e. weight gain and/or obesity) and the stimulation of proinflammatory signaling in distal tissues. Furthermore, it is well documented that HFD directly contributes to intestinal inflammation (de La Serre et al. 2010, Guo et al. 2013), which in turn can impair nutrient assimilation (Semrin et al. 2006). This review discusses dietary options to combat intestinal inflammation in other sections (see 'Suppression of intestine inflammation' and 'Intestine and Insulin-sensitization' section); however, at present it is unclear whether dietary components such as phytoactive chemicals, fibers, and/or antioxidant vitamins/minerals can help protect against HFD-induced excessive fat absorption, alterations in intestinal morphology, and/or reverse impairments to nutrient absorption. Continued research to investigate any benefit of such nutrients in this manner would be greatly beneficial in further understanding the underlying mechanisms of HFDinduced/obesity-associated metabolic impairments and more importantly, combat such disturbances to potentially protect normal/healthy intestine function. Nonetheless, to support the intestinal and overall health it is recommended to consume a diet low in fat and high in foods such as bran cereal fiber, vegetables, fruits, and tea (Weisburger 1997, Ley et al. 2014, Via \& Mechanick 2016) (DRIs, USDA).

\section{Nutritional approaches for insulin sensitization}

Alongside obesity, rates of diabetes have also drastically risen over the previous decades. In fact, the CDC currently estimates that 29 million Americans have diabetes, with roughly $95 \%$ of these cases being T2DM. As such, much research has investigated how to combat the onset of such a disorder both systemically and in specific tissues. Therefore, this section discusses specific consequences of insulin resistance and provides examples of successful nutrient interventions that help regulate impaired insulin signaling and/or protect against the onset of T2DM systemically. In this section, the mechanistic insights are focused on key tissues/organs that are essential for the regulation of systemic insulin sensitivity (Figs. 2, 3, and 5).

\section{Systemic effects}

T2DM/insulin resistance if not monitored can be very dangerous. Abnormal insulin signaling and thus, insufficient glucose uptake can be disastrous to many cell types and tissues that require glucose as a primary source of energy, such as the brain, red blood cells, and kidneys. Further, insulin resistance is known to impair normal metabolic signaling in primary tissues involved in glucose homeostasis. For example, in skeletal muscle, the major organ for glucose utilization, impaired insulin signaling leads to reduced glycogen synthesis (Nikoulina et al. 2001) which can greatly contribute to hyperglycemia. T2DM, especially when paired with obesity, can also severely interfere with normal nutrient-sensing mechanisms (Breen et al. 2011) and lipid metabolism (Harmel et al. 2014). All of these systemic impairments in turn exacerbate T2DM, and can lead to a vicious cycle of insulin resistance and metabolic dysfunction.

Several micronutrients are known to improve systemic insulin signaling in humans, even in the presence of obesity. For example, supplementation with vitamins $\mathrm{D}$ and $\mathrm{E}$ helps improve homeostasis model assessments of insulin resistance (HOMA-IR) scores (Manning et al. 2004, Belenchia et al. 2013, Talaei et al. 2013), which is indicative of overall improved insulin sensitivity. High doses of thiamin/vitamin B1 (Luong \& Nguyen 2012, Alaei Shahmiri et al. 2013) and several minerals (Jayawardena et al. 2012, Rodríguez-Moran \& GuerreroRomero 2014) are also suggested to prevent or slow the progression of hyperglycemia toward diabetes. Other 
dietary components have also recently been implicated in the management of obesity-related diseases in rodent models of obesity. Specifically, polyphenolics such as apple extract and the green tea extract epigallocatechin3-gallate (EGCG) serve to not only lower HOMA-IR scores but exert anti-obesogenic properties as well (Brown et al. 2009, Santamarina et al. 2015).

In a study involving insulin-resistant human subjects, consumption of cod protein diet for 4 weeks was shown to cause a significant increase in insulin sensitivity in relative to consumption of a similar diet containing lean beef, pork, veal, eggs, milk, and milk products (Ouellet et al. 2007). Although encouraging, the study, however, could not completely rule out a contribution of n-3 PUFAs to the improvement in insulin sensitivity; however, n-3 PUFAs did not improve insulin sensitivity in several trials (Itariu et al. 2012, Spencer et al. 2013). As fat mass correlates well with systemic insulin resistance, many trials also analyzed changes in insulin sensitivity while examining dietary effects on weight loss. This was particularly true for trials involving MUFAs as described in section 'Adipose tissue and reduction of adiposity' (Paniagua et al. 2007, Due et al. 2008). Overall, the insulinsensitizing effects of nutritional approaches are highly associated with its effects on suppressing inflammation and/or reducing fat deposition.

\section{Adipose tissue and insulin-sensitization}

Under normal conditions, the adipose tissue secretes a regulated amount of adipokines, such as leptin and adiponectin, both of which are involved in neuroendocrine control of appetite and behavior of food intake. Dietary fat is stored in the adipose tissue as triglycerides, which consequently leads to decreased circulating FFAs. However, in pathological states such as overnutrition and particularly, overnutrition-induced obesity, increased triglyceride deposition in adipocytes leads to abnormal adipocyte metabolism and increased secretion of adipokines. Particularly, there are increased secretions of MCP-1 (Sartipy \& Loskutoff 2003) and other cytokines including TNF $\alpha$ and IL-1 $\beta$, secreted by both adipocytes and recruited macrophages. Increased levels of these cytokines are highly associated with increased lipolysis and decreased triglyceride synthesis. Consequently, elevated circulating FFAs damage pancreatic beta cells and reduce insulin secretion, and exacerbate hyperglycemia of T2DM.

Given that obesity is highly linked with T2DM, research to fully understand the pathology and/or focus on preventative/therapeutic benefits has greatly increased. Therefore, investigating dietary factors that may protect against the development of insulin resistance is paramount. Interestingly, both DHA and resveratrol are known to decrease angiogenesis within the adipose tissue and improve insulin sensitivity, primarily through activation of SIRT1 (Luo et al. 2016), which is a deacetylase that regulates expressions of genes involved in insulin secretion and adipocyte metabolism, among others. Furthermore, Chardonnay grape seed flour, which contains high amounts of flavonoids, is shown to ameliorate obesity and insulin resistance, and improve glucose tolerance in diet-induced obese mice via the modulation of genes within the adipose tissue (Seo et al. 2015). The potential use of additional functional food components for combating insulin resistance in the adipose tissue will be interesting to investigate, particularly for any potential combination therapeutic treatments.

\section{Hepatic regulation of insulin resistance}

In the liver, normal insulin signaling transduces a cascade of actions that properly stimulate or inhibit glucose and fat metabolism, including stimulating glycolysis, glycogenesis, and lipogenesis, while inhibiting gluconeogenesis and glycogenolysis. During insulin resistance however, the signaling molecules within these cascades become impaired/inhibited by various factors including inflammatory mediators such as TNF- $\alpha$, IL- 6 , and IL-1 $\beta$ and result in a loss of insulin signaling (Hirosumi et al. 2002, Gregor \& Hotamisligil 2011).

However, dietary factors again prove to be beneficial in regulating these metabolic pathways. Specifically, fatty acids and micronutrients protect against insulin resistance in the liver both preventing the loss of insulin signaling molecules and reducing the generation of inflammation. For instance, n-3 PUFAs are shown to increase the liver expression of IRS-1 and GLUT2 (Hein et al. 2012 \& Bargut et al. 2014), and also decrease the liver inflammatory status, via increased production of resolvins, to improve insulin sentivity (GonzálezPériz et al. 2009). Similar to n-3 PUFAs, palmitoleate is also shown to improve insulin sensitivty at both hepatic and systemic levels in mice (Guo et al. 2012). This insulin-senstizing effect is attributable to, at least in part, the anti-inflammatory effect of palmitoleate. However, palmitoleate supplementation increases hepatic lipogenic program through enhancing the transcription activity of SREBP1c, leading to an increase in hepatic 
fat deposition. Although processing unwanted effects, palmitoleate, in combination with other nutrients, may still offer benefits similar to those achieved by Mediterranean diets (Mashek \& Wu 2015). Additional to fatty acids, vitamin D can also improve the hepatic insulin resistance likely by improving the inflammatory status of immune cells such as macrophages (Sung et al. 2012). Some evidence suggests that folic acid may also have this effect (Buettner et al. 2010); however, further investigations to fully understand the mechanisms of folic acid are warranted.

\section{Intestine and insulin-sensitization}

It is now well established that inflammation can significantly contribute to insulin resistance, both systemically and within specific tissues. This is also true within the small intestine. Overnutrition with saturated fat can be particularly causative (Rivellese et al. 2002) as saturated fat can stimulate multiple pro-inflammatory mechanisms. For instance, TLR4 expression, which is shown to be a key factor in the development of insulin resistance in many insulin-sensitive tissues, is increased in response to high saturated fat intake in small intestine. The interactions between HFD and bacterial populations with the intestinal tract are also associated with insulin resistance. For example, mice with conventional bacteria fed on HFD express significantly higher levels of TNF $\alpha$, a well-known inhibitor of insulin signaling, compared to germ-free mice fed on the same diet (Ding et al. 2010). Furthermore, it has been shown that short-term HFD feeding leads to the translocation of commensal bacteria from the intestine to adipose tissue, which contributes to the development of inflammation and HFD-induced systemic hyperglycemia (Amar et al. 2011). Thus, the intestine can both directly and indirectly contribute to the development of systemic insulin resistance within the diet-induced obese model, as it not only exhibits impaired insulin signaling itself, but also serves as a mediator for the onset of insulin resistance in distal tissues.

Regarding interventions to alleviate insulin resistance through targeting the small intestine, it seems the best approach is to reduce/prevent the generation of inflammation. Ingestion of vitamin $\mathrm{E}$ for example helps reduce the formation of free radicals within the intestine and thus, attenuates lipid peroxidation and protein oxidation to thereby reduce inflammation (Shirpoor et al. 2007). Additional dietary treatments to reduce intestine inflammation are discussed above in section 'Suppression of Intestine Inflammation'. However, non-dietary treatments have been suggested as well. For example, direct treatment with anti-inflammatory cytokines can greatly improve the intestinal environment and protect against systemic insulin resistance. Specifically, interleukin 22 (IL-22) not only decreases endotoxemia and inflammation, but also serves to preserve the gut mucosal barrier and improve the systemic insulin sensitivity (Wang et al. 2014). IL-22 expression and/or activity are reduced in the obese phenotype (Wang et al. 2014) therefore, treatment with this cytokine in patients with obesityassociated insulin resistance could drastically improve their impaired metabolic state. In addition, it is recently well documented that an HFD also induces phenotypic shifts within the intestinal microbiome that in turn, contribute to the development of obesity and systemic insulin resistance (Turnbaugh et al. 2006, Cani et al. 2008, Cani et al. 2009, Patrice \& Nathalie 2009). Therefore, interventions to retain commensal bacterial populations can also regulate the generation of inflammation and onset of insulin resistance. In fact, many studies have demonstrated that prebiotics and/or probiotics can counteract the negative metabolic effects and associated metabolic disorders induced by HFD (Everard et al. 2011, Park et al. 2013, Toral et al. 2014, Wang et al. 2015a).

\section{Feeding behavior and physical activity}

The most effective way to prevent obesity-related metabolic diseases appears to be to prevent the development of obesity or to promote weight loss. Many pharmaceutical and herbal products exist for weight loss, promising 'fast results' or 'rapid weight loss'. Unfortunately no 'quick fix' for weight loss exists. Healthy weight loss however, although a slower process, is greatly beneficial for overall health and metabolism and more importantly, is more sustainable. The most effective interventions to achieve such weight loss, and prevent weight gain in the already overweight/obese, are caloric restriction and physical activity. This section will discuss each intervention and outline the specific metabolic benefits each has to offer.

\section{Caloric restriction}

Caloric restriction (CR) involves negative energy balance short of malnutrition or deficiency of essential nutrients. It is a dietary intervention that can improve health and extend the life span in many species, including rodents, primates and humans (Heilbronn \& Ravussin 2003, Colman et al. 2014). In addition to inducing weight-loss,

Published by Bioscientifica Ltd. 
CR is shown to improve glycemic control and insulin sensitivity in obese diabetic patients (Wing et al. 1994, Markovic et al. 1998). Similar results were also obtained in a randomized controlled trial involving obese infertile women (Becker et al. 2015). Even in non-obese healthy adults, 2-year CR results in 10\% weight loss without negatively altering life quality (Martin et al. 2016). Similarly in healthy adults, Sparks et al. demonstrated that 12-month CR does not improve muscle mitochondrial functions, but appears to significantly decrease plasma levels of insulin and tends to decrease plasma levels of glucose, which likely indicate improvement of insulin sensitivity (Sparks et al. 2017). Of interest, CR per se is a significant factor in generating metabolic benefits during weight loss in obese and diabetic patients (Wing RR et al. 1994). A similar study has further suggested that the beneficial effects of CR on insulin action and glycemic control are related to changes in individual macronutrients. The latter is different from weight loss, whose beneficial effects are related to changes in abdominal fat (Markovic $\mathrm{TP}$ et al. 1998). According to accumulating evidence, it seems that CR is beneficial in this manner for both obese and normal-weight subjects, with and without diabetes. For example, one study found that obese, non-diabetic human adults on an acute CR diet for 5 days had improved skeletal muscle insulin sensitivity via enhanced insulin signaling molecules (Wang et al. 2012). In addition, studies demonstrate that $\mathrm{CR}$ can also protect cardiovascular/ endothelial function in obesity. For example, short-term CR of $80 \%$ in obese rats ameliorates impaired endothelial function and reduces systolic blood pressure ad libitum (García-Prieto et al. 2015). The likely mechanism seems that reduced caloric and/or nutrient intake stimulates endothelial AMPK activity and subsequently leads to activation of the PI3K-Akt-eNOS pathway. CR also improves ventricular hypertrophy, fibrosis, and diastolic dysfunction, and decreases the expression of angiotensin converting enzyme and angiotensin II type $1 \mathrm{~A}$ receptor genes in the heart of obese rats (Takatsu et al. 2013).

Given that inflammation is a major underlying factor of obesity and obesity-related diseases, much research has also investigated how CR may regulate the generation of inflammation. For instance, CR is viewed as a way to counter systemic inflammation caused by the adipose tissue expansion (Ye \& Keller 2010). To date, many studies have investigated this using both human and animal models of HFD-induced obesity, given the association between overnutrition and inflammation and/ or the onset of obesity. Widespread results show that CR reduces HFD-induced proinflammatory markers, such as proinflammatory cytokines and $\mathrm{NF \kappa B}$, and the production of oxidative stress (Park et al. 2012, Wasinski et al. 2013). These findings are also true in clinical studies on diabetic, morbidly obese patients. For example, acute CR (400 kCal less/day) for 7 days reduced inflammation, improved insulin sensitivity and improved renal function (Giordani et al. 2014). However, it should be noted that CR could cause adverse effects in some populations, such as the elderly or low BMI, diabetic patients receiving insulin (Darmon et al. 2010). Nonetheless, careful consideration and proper physician supervision should always be taken for any individual following such a diet plan (Buchowski et al. 2012, Bhardwaj et al. 2013, Takatsu et al. 2013, Tomada et al. 2013).

\section{Physical activity and caloric restriction}

Physical activity significantly increases energy expenditure and therefore is commonly used an intervention for weight loss and/or preventing weight gain. This intervention is especially beneficial for obese individuals (Jakicic \& Otto 2005, Fock \& Khoo 2013, Baillot et al. 2015, Chin et al. 2016), who commonly lead an overall sedentary lifestyle. In fact, physical activity is the most highly recommended intervention to prevent and slow weight gain, and lower BMI in obese children (Alkon et al. 2014, BautistaCastaño et al. 2004, Lee et al. 2012). Furthermore, physical activity is not only beneficial for weight loss. A vast number of studies have demonstrated that physical activity is greatly beneficial in maintaining and promoting overall health via increased cardiovascular efficiency, insulin signaling in skeletal muscle, and in young individuals in preventing osteoporosis (Bassuk \& Manson 2005, Borer 2005, Klein et al. 2004, Roberts et al. 2006).

Due to the beneficial abilities of CR and physical activity, independently, in preventing and/or combating obesity and obesity-associated disorders, numerous studies have investigated the effect of a combination intervention on such disorders. Unsurprisingly, results of such studies demonstrate positive results. For example, exercise and CR together can help lower the obesity index by reducing visceral fat, reduce levels of serum biomarkers such as LDL and triglycerides, and decrease inflammatory indicators (Ekuni et al. 2014, Vissers et al. 2013). Further, a combined intervention can reduce cardiovascular risks in obese individuals diagnosed with metabolic syndrome (Dutheil et al. 2013). Several studies report that a combination of exercise and CR exerts more beneficial effects than either physical activity or CR alone (Wang et al. 2015b). Such combination interventions are also useful approaches for

Published by Bioscientifica Ltd. 
preventing the complications of NAFLD, commonly seen in the obese (Nseir et al. 2014).

\section{Childhood obesity}

Obesity remains a global epidemic. Alarmingly, the percentage of children with obesity in the United States has more than tripled since the 1970s, based on the Childhood Obesity Facts released by the CDC. The situation is even worse in developing countries including China, where the percentage of childhood obesity increases much greater and faster. Given the difficulty in reducing body weight once obesity is established, it is considered as an urgent need to initiate prevention and treatment of obesity in children (Dehghan et al. 2005). As demonstrated by numerous studies, total diet and physical activity level of a child critically determine a child's body weight. Therefore, nutrition approaches are crucial for prevention of childhood obesity. It is equally important to establish and enforce programs to increase physical activities in both pre-school and school-age children. The pertinent details have been described elsewhere, and are not discussed here.

\section{Conclusion}

The increase in the incidence of obesity makes obesity and its related metabolic diseases a huge problem in public health. Over the past several decades, mounting evidence obtained from both basic and clinical research has much advanced our understanding of the pathogenesis of metabolic diseases and led to the validation and application of nutritional approaches for managing metabolic diseases. As described above, nutritional approaches are commonly used for suppressing inflammation, improving insulin sensitivity, and/or decreasing fat deposition (Fig. 5). Although promising, the current approaches are also challenged by existing and new issues, e.g., poor long-term efficacy and reproducibility, and increased prevalence of childhood obesity. Another significant challenge is that human studies, in relation to animal studies, often have limitations in methodologies, which prevents performing insightful experiments to establish cause-and-effect relationships. To solve the issues, many efforts are needed to enhance the nutrition research. In particular, basic and clinical nutrition research is needed to extensively investigate how various diet compositions differentially alter metabolic homeostasis. There is also a need to conduct long-term randomized and controlled trials to firmly establish the beneficial effects of nutritional approaches. Furthermore, how such factors may differ within the context of childhood and adolescent obesity is of paramount importance. Lastly, it might be a time now for a philosophic change: to use nutritional approaches, together with healthy lifestyle at all ages, for promoting health and preventing obesity and metabolic diseases, not for treating metabolic diseases.

\section{Declaration of interest}

The authors declare that there is no conflict of interest that could be perceived as prejudicing the impartiality of this review.

\section{Funding}

This research did not receive any specific grant from any funding agency in the public, commercial, or not-for-profit sector.

\section{Acknowledgements}

The authors thank the Deputy Editor and editorial board for the invitation to contribute this review article. This work was supported in part by grants from the National Institutes of Health (R01DK095828 and R01DK095862) and American Diabetes Association (1-17-IBS-145) (to C.W.). Also, C.W. is supported by the Hatch Program of the National Institutes of Food and Agriculture (NIFA).

\section{References}

Abdullahi A \& Jeschke MG 2016 White Adipose tissue browning: a double-edged sword. Trends in Endocrinology \& Metabolism 27 542-552. (doi:10.1016/j.tem.2016.06.006)

Aggarwal BB 2010 Targeting inflammation-induced obesity and metabolic diseases by curcumin and other nutraceuticals. Annual Review of Nutrition 30 173-199. (doi:10.1146/annurev.nutr.012809.104755)

Al Masri M, Romain AJ, Boegner C, Maimoun L, Mariano-Goulart D, Attalin V, Leprieur E, Picandet M, Avignon A \& Sultan A 2017 Vitamin $\mathrm{D}$ status is not related to insulin resistance in different phenotypes of moderate obesity. Applied Physiology, Nutrition, and Metabolism 42 438-442. (doi:10.1139/apnm-2016-0298)

Alaei Shahmiri F, Soares MJ, Zhao Y \& Sherriff J 2013 High-dose thiamine supplementation improves glucose tolerance in hyperglycemic individuals: a randomized, double-blind cross-over trial. European Journal of Nutrition 52 1821-1824. (doi:10.1007/s00394-013-0534-6)

Alghasham A, Salem TA \& Meki A-RM 2013 Effect of cadmium-polluted water on plasma levels of tumor necrosis factor- $\alpha$, interleukin- 6 and oxidative status biomarkers in rats: protective effect of curcumin. Food and Chemical Toxicology 59 160-164. (doi:10.1016/j.fct.2013.05.059)

Alkon A, Crowley AA, Neelon SEB, Hill S, Pan Y, Nguyen V, Rose R, Savage E, Forestieri N, Shipman L, et al. 2014 Nutrition and physical activity randomized control trial in child care centers improves knowledge, policies, and children's body mass index. BMC Public Health 14215. (doi:10.1186/1471-2458-14-215)

Amar J, Chabo C, Waget A, Klopp P, Vachoux C, Bermúdez-Humarán LG, Smirnova N, Bergé M, Sulpice T, Lahtinen S, et al. 2011 Intestinal mucosal adherence and translocation of commensal bacteria at the early onset of type 2 diabetes: molecular mechanisms and probiotic

Published by Bioscientifica Ltd. 
treatment. EMBO Molecular Medicine 3 559-572. (doi:10.1002/ emmm.201100159)

Ambrosini GL, Emmett PM, Northstone K, Howe LD, Tilling K \& Jebb SA 2012 Identification of a dietary pattern prospectively associated with increased adiposity during childhood and adolescence. International Journal of Obesity 36 1299-1305. (doi:10.1038/ ijo.2012.127)

Anstee QM \& Goldin RD 2006 Mouse models in non-alcoholic fatty liver disease and steatohepatitis research. International Journal of Experimental Pathology 87 1-16. (doi:10.1111/j.0959. 9673.2006.00465.x)

Appel LJ, Sacks FM, Carey VJ, Obarzanek E, Swain JF, Miller ER, Conlin PR, Erlinger TP, Rosner BA, Laranjo NM, et al. 2005 Effects of protein, monounsaturated fat, and carbohydrate intake on blood pressure and serum lipids: results of the omniheart randomized trial. JAMA 294 2455-2464. (doi:10.1001/jama.294.19.2455)

Argiana V, Kanellos PT, Makrilakis K, Eleftheriadou I, Tsitsinakis G, Kokkinos A, Perrea D \& Tentolouris N 2015 The effect of consumption of low-glycemic-index and low-glycemic-load desserts on anthropometric parameters and inflammatory markers in patients with type 2 diabetes mellitus. European Journal of Nutrition $\mathbf{5 4}$ 1173-1180. (doi:10.1007/s00394-014-0795-8)

Arkan MC, Hevener AL, Greten FR, Maeda S, Li Z-W, Long JM, Wynshaw-Boris A, Poli G, Olefsky J \& Karin M 2005 IKK-[beta] links inflammation to obesity-induced insulin resistance. Nature Medicine 11 191-198. (doi:10.1038/nm1185)

Astrup A \& Bugel S 2010 Micronutrient deficiency in the aetiology of obesity. International Journal of Obesity 34 947-948. (doi:10.1038/ ijo.2010.81)

Azrad M, Turgeon C \& Demark-Wahnefried W 2013 Current Evidence Linking Polyunsaturated Fatty Acids with Cancer Risk and Progression. Frontiers in Oncology 3 224. (doi:10.3389/ fonc.2013.00224)

Baillot A, Romain AJ, Boisvert-Vigneault K, Audet M, Baillargeon JP, Dionne IJ, Valiquette L, Chakra CNA, Avignon A \& Langlois M-F 2015 Effects of lifestyle interventions that include a physical activity component in class II and III obese individuals: a systematic review and meta-analysis. PLOS ONE 10 e0119017. (doi:10.1371/journal pone.0119017)

Banin RM, Hirata BKS, Andrade IS, Zemdegs JCS, Clemente APG, Dornellas APS, Boldarine VT, Estadella D, Albuquerque KT, Oyama LM, et al. 2014 Beneficial effects of Ginkgo biloba extract on insulin signaling cascade, dyslipidemia, and body adiposity of diet-induced obese rats. Brazilian Journal of Medical and Biological Research 47 780-788. (doi:10.1590/1414-431X20142983)

Bannenberg GL, Chiang N, Ariel A, Arita M, Tjonahen E, Gotlinger KH Hong S \& Serhan CN 2005 Molecular circuits of resolution: formation and actions of resolvins and protectins. Journal of Immunology $\mathbf{1 7 4}$ 4345-4355. (doi:10.4049/jimmunol.174.7.4345)

Bargut TCL, Frantz EDC, Mandarim-de-Lacerda CA \& Aguila MB 2014 Effects of a diet rich in n-3 polyunsaturated fatty acids on hepatic lipogenesis and beta-oxidation in mice. Lipids 49 431-444. (doi:10.1007/s11745-014-3892-9)

Barroso E, Rodríguez-Calvo R, Serrano-Marco L, Astudillo AM, Balsinde J, Palomer X \& Vázquez-Carrera M 2011 The PPAR $\beta / \delta$ Activator GW501516 prevents the down-regulation of AMPK caused by a high-fat diet in liver and amplifies the PGC-1 $\alpha$-Lipin 1-PPARo pathway leading to increased fatty acid oxidation. Endocrinology 152 1848-1859. (doi:10.1210/en.2010-1468)

Bartelt A \& Heeren J 2014 Adipose tissue browning and metabolic health. Nature Reviews Endocrinology 10 24-36. (doi:10.1038/ nrendo.2013.204)

Bassuk SS \& Manson JE 2005 Epidemiological evidence for the role of physical activity in reducing risk of type 2 diabetes and cardiovascular disease. Journal of Applied Physiology 99 1193. (doi:10.1152/ japplphysiol.00160.2005)
Bautista-Castaño I, Doreste J \& Serra-Majem L 2004 Effectiveness of interventions in the prevention of childhood obesity. European Journal of Epidemiology 19 617-622.

Becker GF, Passos EP \& Moulin CC 2015 Short-term effects of a hypocaloric diet with low glycemic index and low glycemic load on body adiposity, metabolic variables, ghrelin, leptin, and pregnancy rate in overweight and obese infertile women: a randomized controlled trial. American Journal of Clinical Nutrition 102 1365-1372. (doi:10.3945/ajcn.115.117200)

Belenchia AM, Tosh AK, Hillman LS \& Peterson CA 2013 Correcting vitamin D insufficiency improves insulin sensitivity in obese adolescents: a randomized controlled trial. American Journal of Clinical Nutrition 97 774-781. (doi:10.3945/ajcn.112.050013)

Berg AH \& Scherer PE 2005 Adipose tissue, Inflammation, and Cardiovascular disease. Circulation Research 96 939. (doi:10.1161/01. RES.0000163635.62927.34)

Bhardwaj P, Du B, Zhou XK, Sue E, Harbus MD, Falcone DJ, Giri D, Hudis CA, Kopelovich L, Subbaramaiah K, et al. 2013 Caloric restriction reverses obesity-induced mammary gland inflammation in mice. Cancer Prevention Research 6 282. (doi:10.1158/1940-6207.CAPR-12-0467)

Bhaskaran K, Douglas I, Forbes H, dos-Santos-Silva I, Leon DA \& Smeeth L 2014 Body-mass index and risk of 22 specific cancers: a populationbased cohort study of 5.24 million UK adults. Lancet 384 755-765. (doi:10.1016/S0140-6736(14)60892-8)

Bishop KS \& Ferguson LR 2015 The interaction between epigenetics, nutrition and the development of cancer. Nutrients 7 922-947. (doi:10.3390/nu7020922)

Bleau C, Karelis AD, St-Pierre DH \& Lamontagne L 2015 Crosstalk between intestinal microbiota, adipose tissue and skeletal muscle as an early event in systemic low-grade inflammation and the development of obesity and diabetes. Diabetes/Metabolism Research and Reviews 31 545-561. (doi:10.1002/dmrr.2617)

Bordoni A, Di Nunzio M, Danesi F \& Biagi PL 2006 Polyunsaturated fatty acids: From diet to binding to ppars and other nuclear receptors. Genes \& Nutrition 1 95-106. (doi:10.1007/bf02829951)

Borer KT 2005 Physical activity in the prevention and amelioration of osteoporosis in women. Sports Medicine 35 779-830. (doi:10.2165/00007256-200535090-00004)

Botchlett R, Li H, Guo X, Qi T, Zhao J, Zheng J, Woo S-L, Pei Y, Liu M, Hu $\mathrm{X}$, et al. 2016 Glucose and palmitate differentially regulate PFKFB3/ iPFK2 and inflammatory responses in mouse intestinal epithelial cells. Scientific Reports 6 28963. (doi:10.1038/srep28963)

Breen DM, Yang CS \& Lam TKT 2011 Gut-brain signalling: how lipids can trigger the gut. Diabetes/Metabolism Research and Reviews 27 113-119. (doi:10.1002/dmrr.1160)

Brown AL, Lane J, Coverly J, Stocks J, Jackson S, Stephen A, Bluck L, Coward A \& Hendrickx H 2009 Effects of dietary supplementation with the green tea polyphenol epigallocatechin-3-gallate on insulin resistance and associated metabolic risk factors: randomized controlled trial. British Journal of Nutrition 101 886-894. (doi:10.1017/ S0007114508047727)

Buchowski MS, Hongu N, Acra S, Wang L, Warolin J \& Roberts LJ, II 2012 Effect of modest caloric restriction on oxidative stress in women, a randomized trial. PLoS ONE 7 e47079. (doi:10.1371/journal. pone.0047079)

Buettner R, Bettermann I, Hechtl C, Gäbele E, Hellerbrand C, Schölmerich J \& Bollheimer LC 2010 Dietary folic acid activates AMPK and improves insulin resistance and hepatic inflammation in dietary rodent models of the metabolic syndrome. Hormone and Metabolic Research 42 769-774. (doi:10.1055/s-0030-1263122)

Cai D, Yuan M, Frantz DF, Melendez PA, Hansen L, Lee J \& Shoelson SE 2005 Local and systemic insulin resistance resulting from hepatic activation of IKK- $\beta$ and NF-кB. Nature Medicine 11 183-190. (doi:10.1038/nm1166)

Calder PC 2010 Omega-3 Fatty Acids and Inflammatory Processes. Nutrients 2 355-374. (doi:10.3390/nu2030355) 
Cani PD, Bibiloni R, Knauf C, Waget A, Neyrinck AM, Delzenne NM \& Burcelin R 2008 Changes in gut microbiota control metabolic endotoxemia-induced inflammation in high-fat diet-induced obesity and diabetes in mice. Diabetes 57 1470. (doi:10.2337/ db07-1403)

Cani PD, Possemiers S, Van de Wiele T, Guiot Y, Everard A, Rottier O, Geurts L, Naslain D, Neyrinck A, Lambert DM, et al. 2009 Changes in gut microbiota control inflammation in obese mice through a mechanism involving GLP-2-driven improvement of gut permeability. Gut 58 1091-1103. (doi:10.1136/gut.2008.165886)

Carreiro AL, Dhillon J, Gordon S, Higgins KA, Jacobs AG, McArthur BM, Redan BW, Rivera RL, Schmidt LR \& Mattes RD 2016 The macronutrients appetite, and energy intake. Annual Review of Nutrition 36 73-103. (doi:10.1146/annurev-nutr-121415-112624)

Cawley J \& Meyerhoefer C 2012 The medical care costs of obesity: an instrumental variables approach. Journal of Health Economics $\mathbf{3 1}$ 219-230. (doi:10.1016/j.jhealeco.2011.10.003)

Chin SH, Kahathuduwa CN \& Binks M 2016 Physical activity and obesity: what we know and what we need to know. Obesity Reviews 17 1226-1244. (doi:10.1111/obr.12460)

Cho I \& Blaser MJ 2012 The Human Microbiome: at the interface of health and disease. Nature Reviews Genetics 13 260-270. (doi:10.1038/ nrg3182)

Choi S, Choi Y, Choi Y, Kim S, Jang J \& Park T 2013 Piperine reverses high fat diet-induced hepatic steatosis and insulin resistance in mice. Food Chemistry 141 3627-3635. (doi:10.1016/j.foodchem.2013.06.028)

Chu CA, Sherck SM, Igawa K, Sindelar DK, Neal DW, Emshwiller M \& Cherrington AD 2002 Effects of free fatty acids on hepatic glycogenolysis and gluconeogenesis in conscious dogs. American Journal of Physiology: Endocrinology And Metabolism 282 E402. (doi:10.1152/ajpendo.00136.2001)

Colman RJ, Beasley TM, Kemnitz JW, Johnson SC, Weindruch R \& Anderson RM 2014 Caloric restriction reduces age-related and allcause mortality in rhesus monkeys. Nature Communications 53557. (doi:10.1038/ncomms4557)

Corbin KD \& Zeisel SH 2012 Choline metabolism provides novel insights into non-alcoholic fatty liver disease and its progression. Current Opinion in Gastroenterology 28 159-165. (doi:10.1097/ MOG.0b013e32834e7b4b)

Couet C, Delarue J, Ritz P, Antoine JM \& Lamisse F 1997 Effect of dietary fish oil on body fat mass and basal fat oxidation in healthy adults. International Journal of Obesity 21 637-643. (doi:10.1038/ sj.ijo.0800451)

Dailey MJ 2014 Nutrient-induced intestinal adaption and its effect in obesity. Physiology \& Behavior 136 74-78. (doi:10.1016/j. physbeh.2014.03.026)

Darmon P, Kaiser MJ, Bauer JM, Sieber CC \& Pichard C 2010 Restrictive diets in the elderly: never say never again? Clinical Nutrition 29 170-174. (doi:10.1016/j.clnu.2009.11.002)

de La Serre CB, Ellis CL, Lee J, Hartman AL, Rutledge JC \& Raybould HE 2010 Propensity to high-fat diet-induced obesity in rats is associated with changes in the gut microbiota and gut inflammation. American Journal of Physiology: Gastrointestinal and Liver Physiology 299 G440-G448. (doi:10.1152/ajpgi.00098.2010)

Dehghan M, Akhtar-Danesh N \& Merchant AT 2005 Childhood obesity, prevalence and prevention. Nutrition Journal 4 24. (doi:10.1186/14752891-4-24)

den Besten G, van Eunen K, Groen AK, Venema K, Reijngoud D-J \& Bakker BM 2013 The role of short-chain fatty acids in the interplay between diet, gut microbiota, and host energy metabolism. Journal of Lipid Research 54 2325-2340. (doi:10.1194/jlr.R036012)

Ding S, Chi MM, Scull BP, Rigby R, Schwerbrock NMJ, Magness S, Jobin C \& Lund PK 2010 High-Fat Diet: bacteria interactions promote intestinal inflammation which precedes and correlates with obesity and insulin resistance in mouse. PLoS ONE 5 e12191. (doi:10.1371/ journal.pone.0012191)
Domínguez Coello S, Cabrera de León A, Rodríguez Pérez MC, Borges Álamo C, Carrillo Fernández L, Almeida González D, García Yanes J, González Hernández A, Brito Díaz B \& Aguirre-Jaime A 2010 Association between glycemic index, glycemic load, and fructose with insulin resistance: the CDC of the Canary Islands study. European Journal of Nutrition 49 505-512. (doi:10.2337/diacare.28.12.2986)

Du Z-Y, Wei X, Huang M-T, Zheng X, Liu Y, Conney AH \& Zhang K 2013 Anti-proliferative, anti-inflammatory and antioxidant effects of curcumin analogue A2. Archives of Pharmacal Research 36 1204-1210. (doi:10.1007/s12272-013-0216-1)

Du S, Jin J, Fang W \& Su Q 2015 Does fish oil have an anti-obesity effect in overweight/obese adults? a meta-analysis of randomized controlled trials. PLOS ONE 10 e0142652. (doi:10.1371/journal. pone.0142652)

Due A, Larsen TM, Mu H, Hermansen K, Stender S \& Astrup A 2008 Comparison of 3 ad libitum diets for weight-loss maintenance, risk of cardiovascular disease, and diabetes: A 6-mo randomized, controlled trial. American Journal of Clinical Nutrition 88 1232-1241.

Dutheil F, Lac G, Lesourd B, Chapier R, Walther G, Vinet A, Sapin V, Verney J, Ouchchane L, Duclos M, et al. Different modalities of exercise to reduce visceral fat mass and cardiovascular risk in metabolic syndrome: the RESOLVE* randomized trial. International Journal of Cardiology 168 3634-3642. (doi:10.1016/j. ijcard.2013.05.012)

Egger G 2012 In search of a germ theory equivalent for chronic disease. Preventing Chronic Disease 9 E95. (doi:10.5888/pcd9.110301)

Ekuni D, Mizutani S, Kojima A, Tomofuji T, Irie K \& Azuma T 2014 Relationship between increases in BMI and changes in periodontal status: a prospective cohort study. Journal of Clinical Periodontology 41 772-778. (doi:10.1111/jcpe.12273)

Emilsson V, Thorleifsson G, Zhang B, Leonardson AS, Zink F, Zhu J, Carlson S, Helgason A, Walters GB, Gunnarsdottir S, et al. 2008 Genetics of gene expression and its effect on disease. Nature $\mathbf{4 5 2}$ 423-428. (doi:10.1038/nature06758)

Esfahani A, Wong JMW, Truan J, Villa CR, Mirrahimi A, Srichaikul K \& Kendall CWC 2011 Health Effects of Mixed Fruit and Vegetable Concentrates: a systematic review of the clinical interventions. Journal of the American College of Nutrition 30 285-294. (doi:10.1080/0731572 4.2011.10719971)

Everard A, Lazarevic V, Derrien M, Girard M, Muccioli GM, Neyrinck AM, Possemiers S, Van Holle A, François P, de Vos WM, et al. 2011 Responses of gut microbiota and glucose and lipid metabolism to prebiotics in genetic obese and diet-induced leptin-resistant mice. Diabetes 60 2775-2786. (doi:10.2337/db11-0227)

Fan J, Heller NM, Gorospe M, Atasoy U \& Stellato C 2005 The role of post-transcriptional regulation in chemokine gene expression in inflammation and allergy. European Respiratory Journal 26 933. (doi:10. 1183/09031936.05.00120204)

Farrokhian A, Raygan F, Bahmani F, Talari HR, Esfandiari R, Esmaillzadeh A \& Asemi Z 2017 Long-term vitamin D supplementation affects metabolic status in vitamin D-deficient type 2 diabetic patients with coronary artery disease. Journal of Nutrition 147 384-389. (doi:10.3945/jn.116.242008)

Flowers MT \& Ntambi JM 2009 Stearoyl-CoA desaturase and its relation to high-carbohydrate diets and obesity. Biochimica et Biophysica ActaMolecular and Cell Biology of Lipids 1791 85-91.

Fock KM \& Khoo J 2013 Diet and exercise in management of obesity and overweight. Journal of Gastroenterology and Hepatology 28 59-63. (doi:10.1111/jgh.12407)

Foster-Powell K, Holt SH \& Brand-Miller JC 2002 International table of glycemic index and glycemic load values: 2002. American Journal of Clinical Nutrition 76 5-56.

Freudenberg A, Petzke KJ \& Klaus S 2013 Dietary l-leucine and l-alanine supplementation have similar acute effects in the prevention of high-fat diet-induced obesity. Amino Acids 44 519-528. (doi:10.1007/ s00726-012-1363-2) 
Furtado JD, Campos H, Appel LJ, Miller ER, Laranjo N, Carey VJ \& Sacks FM 2008 Effect of protein, unsaturated fat, and carbohydrate intakes on plasma apolipoprotein B and VLDL and LDL containing apolipoprotein C-III: results from the OmniHeart Trial. American Journal of Clinical Nutrition 87 1623-1630.

Gadgil MD, Appel LJ, Yeung E, Anderson CAM, Sacks FM \& Miller ER 2013 The Effects of Carbohydrate, Unsaturated Fat, and Protein Intake on Measures of Insulin Sensitivity: results from the omniheart trial. Diabetes Care 36 1132-1137. (doi:10.2337/dc12-0869)

García OP, Long KZ \& Rosado JL 2009 Impact of micronutrient deficiencies on obesity. Nutrition Reviews 67 559. (doi:10.1111/j.17534887.2009.00228.x)

García-Prieto CF, Pulido-Olmo H, Ruiz-Hurtado G, Gil-Ortega M, Aranguez I, Rubio MA, Ruiz-Gayo M, Somoza B \& Fernández-Alfonso MS 2015 Mild caloric restriction reduces blood pressure and activates endothelial AMPK-PI3K-Akt-eNOS pathway in obese Zucker rats. Vascular Pharmacology 65-66 3-12. (doi:10.1016/j.vph.2014.12.001)

George PS, Pearson ER \& Witham MD 2012 Effect of vitamin D supplementation on glycaemic control and insulin resistance: a systematic review and meta-analysis. Diabetic Medicine 29 e142-e150. (doi:10.1111/j.1464-5491.2012.03672.x)

Giordani I, Malandrucco I, Donno S, Picconi F, Di Giacinto P, Di Flaviani A, Chioma L \& Frontoni S 2014 Acute caloric restriction improves glomerular filtration rate in patients with morbid obesity and type 2 diabetes. Diabetes Metab 40 158-160. (doi:10.1016/j. diabet.2013.12.006)

González-Périz A, Planagumà A, Gronert K, Miquel R, López-Parra M, Titos E, Horrillo R, Ferré N, Deulofeu R, Arroyo V, et al. 2006 Docosahexaenoic acid (DHA) blunts liver injury by conversion to protective lipid mediators: protectin D1 and 17S-hydroxy-DHA. FASEB Journal 20 2537-2539. (doi:10.1096/fj.06-6250fje)

González-Périz A, Horrillo R, Ferré N, Gronert K, Dong B, Morán-Salvador E, Titos E, Martínez-Clemente M, López-Parra M, Arroyo V, et al. 2009 Obesity-induced insulin resistance and hepatic steatosis are alleviated by $\omega-3$ fatty acids: a role for resolvins and protectins. FASEB Journal 23 1946-1957. (doi:10.1096/fj.08-125674)

Gregor MF \& Hotamisligil GS 2011 Inflammatory Mechanisms in Obesity. Annual Review of Immunology 29 415-445. (doi:10.1146/annurevimmunol-031210-101322)

Guo X, Li H, Xu H, Halim V, Zhang W, Wang H, Ong KT, Woo S-L, Walzem RL, Mashek DG, et al. 2012 Palmitoleate induces hepatic steatosis but suppresses liver inflammatory response in mice. PLoS ONE 7 e39286. (doi:10.1371/journal.pone.0039286)

Guo X, Li H, Xu H, Halim V, Thomas LN, Woo S-L, Huo Y, Chen YE, Sturino JM \& Wu C 2013 Disruption of inducible 6-phosphofructo2-kinase impairs the suppressive effect of PPAR $\gamma$ activation on diet-induced intestine inflammatory response. Journal of Nutritional Biochemistry 24 770-775. (doi:10.1016/j.jnutbio.2012.04.007)

Guo T, Woo S-L, Guo X, Li H, Zheng J, Botchlett R, Liu M, Pei Y, Xu H, Cai Y, et al. 2016 Berberine ameliorates hepatic steatosis and suppresses liver and adipose tissue inflammation in mice with dietinduced obesity. Scientific Reports 6 22612. (doi:10.1038/srep22612)

Han J, Pan X-Y, Xu Y, Xiao Y, An Y, Tie L, Pan Y \& Li X-J 2012 Curcumin induces autophagy to protect vascular endothelial cell survival from oxidative stress damage. Autophagy 8 812-825. (doi:10.4161/ auto.19471)

Hardy OT, Perugini RA, Nicoloro SM, Gallagher-Dorval K, Puri V, Straubhaar J \& Czech MP 2011 BMI-independent inflammation in omental adipose tissue associated with insulin resistance in morbid obesity. Surgery for Obesity and Related Diseases 7 60-67. (doi:10.1016/j. soard.2010.05.013)

Harmel E, Grenier E, Ouadda AB, Chebly ME, Ziv E, Beaulieu JF, Sané A, Spahis S, Laville M \& Levy E 2014 AMPK in the Small Intestine in Normal and Pathophysiological Conditions. Endocrinology 155 873-888. (doi:10.1210/en.2013-1750)
He C, Shan Y \& Song W 2015a Targeting gut microbiota as a possible therapy for diabetes. Nutrition Research 35 361-367. (doi:10.1016/j. nutres.2015.03.002)

He F, Bixler EO, Liao J, Berg A, Imamura Kawasawa Y, Fernandez-Mendoza J, Vgontzas AN \& Liao D 2015b Habitual sleep variability, mediated by nutrition intake, is associated with abdominal obesity in adolescents. Sleep Medicine 16 1489-1494. (doi:10.1016/j.sleep.2015.07.028)

Heilbronn LK \& Ravussin E 2003 Calorie restriction and aging: review of the literature and implications for studies in humans. American Journal of Clinical Nutrition 78 361-369.

Hein GJ, Chicco A \& Lombardo YB 2012 Fish oil normalizes plasma glucose levels and improves liver carbohydrate metabolism in rats fed a sucrose-rich diet. Lipids 47 141-150. (doi:10.1007/s11745-0113623-4)

Heinritz SN, Weiss E, Eklund M, Aumiller T, Louis S, Rings A, Messner S, Camarinha-Silva A, Seifert J, Bischoff SC, et al. 2016 Intestinal microbiota and microbial metabolites are changed in a pig model fed a high-fat/low-fiber or a low-fat/high-fiber diet. PLOS ONE 11 e0154329. (doi:10.1371/journal.pone.0154329)

Heo J, Seo M, Park H, Lee WK, Guan LL, Yoon J, Caetano-Anolles K, Ahn H, Kim S-Y, Kang Y-M, et al. 2016 Gut microbiota modulated by probiotics and Garcinia cambogia extract correlate with weight gain and adipocyte sizes in high fat-fed mice. Scientific Reports 633566. (doi:10.1038/srep33566)

Higashida K, Kim SH, Jung SR, Asaka M, Holloszy JO \& Han D-H 2013 Effects of resveratrol and SIRT1 on PGC- $1 \alpha$ activity and mitochondrial biogenesis: a reevaluation. PLoS Biology 11 e1001603. (doi:10.1371/ journal.pbio.1001603)

Hirosumi J, Tuncman G, Chang L, Gorgun CZ, Uysal KT, Maeda K, Karin M \& Hotamisligil GS 2002 A central role for JNK in obesity and insulin resistance. Nature 420 333-336. (doi:10.1038/nature01137)

Hörnell A, Lagström H, Lande B \& Thorsdottir I 2013 Protein intake from 0 to 18 years of age and its relation to health: a systematic literature review for the 5th Nordic nutrition recommendations. Food \& Nutrition Research 57 10.3402/fnr.v3457i3400.21083.

Hotamisligil GS 2006 Inflammation and metabolic disorders. Nature $\mathbf{4 4 4}$ 860-867. (doi:10.1038/nature05485)

Hotamisligil GS \& Erbay E 2008 Nutrient sensing and inflammation in metabolic diseases. Nature Reviews Immunology 8 923. (doi:10.1038/ nri2449)

Howell G, Deng X, Yellaturu C, Park EA, Wilcox HG, Raghow R \& Elam MB 2009 N-3 Polyunsaturated fatty acids suppress insulin-induced SREBP-1c transcription via reduced trans-activating capacity of LXR $\alpha$. Biochimica et Biophysica Acta 1791 1190-1196. (doi:10.1016/j. bbalip.2009.08.008)

Huang D, Zhao Q, Liu H, Guo Y \& Xu H 2016 PPAR- $\alpha$ agonist WY-14643 inhibits LPS-induced inflammation in synovial fibroblasts via NF-kB pathway. Journal of Molecular Neuroscience 59 544-553. (doi:10.1007/ s12031-016-0775-y)

Hudgins LC, Hellerstein MK, Seidman CE, Neese RA, Tremaroli JD \& Hirsch J 2000 Relationship between carbohydrate-induced hypertriglyceridemia and fatty acid synthesis in lean and obese subjects. Journal of Lipid Research 41 595-604.

Huo Y, Guo X, Li H, Wang H, Zhang W, Wang Y, Zhou H, Gao Z, Telang S, Chesney J, et al. 2010 Disruption of inducible 6-phosphofructo-2kinase ameliorates diet-induced adiposity but exacerbates systemic insulin resistance and adipose tissue inflammatory response. Journal of Biological Chemistry 285 3713-3721. (doi:10.1074/jbc. M109.058446)

Itariu BK, Zeyda M, Hochbrugger EE, Neuhofer A, Prager G, Schindler K, Bohdjalian A, Mascher D, Vangala S, Schranz M, et al. 2012 Longchain n-3 PUFAs reduce adipose tissue and systemic inflammation in severely obese nondiabetic patients: a randomized controlled trial. American Journal of Clinical Nutrition 96 1137-1149. (doi:10.3945/ ajcn.112.037432) http://joe.endocrinology-journals.org

DOI: 10.1530/JOE-16-0580
๑) 2017 Society for Endocrinology Printed in Great Britain 
Jakicic JM \& Otto AD 2005 Physical activity considerations for the treatment and prevention of obesity. American Journal of Clinical Nutrition 82 226S-229S.

Janssens PLHR, Hursel R, Martens EAP \& Westerterp-Plantenga MS 2013 Acute effects of capsaicin on energy expenditure and fat oxidation in negative energy balance. PLOS ONE 8 e67786. (doi:10.1371/journal. pone.0067786)

Jayawardena R, Ranasinghe P, Galappatthy P, Malkanthi R, Constantine G \& Katulanda P 2012 Effects of zinc supplementation on diabetes mellitus: a systematic review and meta-analysis. Diabetology \& Metabolic Syndrome 4 13. (doi:10.1186/1758-5996-4-13)

Jenkins DJ, Kendall CW, Augustin LS, Franceschi S, Hamidi M, Marchie A, Jenkins AL \& Axelsen M 2002 Glycemic index: overview of implications in health and disease. American Journal of Clinical Nutrition 76 266S-273S.

Joffin N, Jaubert A-M, Durant S, Barouki R, Forest C \& Noirez P 2015 Citrulline counteracts overweight- and aging-related effects on adiponectin and leptin gene expression in rat white adipose tissue. Biochimie Open 1 1-5. (doi:10.1016/j.biopen.2015.05.001)

Jump DB 2008 N-3 polyunsaturated fatty acid regulation of hepatic gene transcription. Current Opinion in Lipidology 19 242-247. (doi:10.1097/ MOL.0b013e3282ffaf6a)

Kant V, Gopal A, Pathak NN, Kumar P, Tandan SK \& Kumar D 2014 Antioxidant and anti-inflammatory potential of curcumin accelerated the cutaneous wound healing in streptozotocin-induced diabetic rats. International Immunopharmacology 20 322-330. (doi:10.1016/j. intimp.2014.03.009)

Kim Y-B, Shulman GI \& Kahn BB 2002 Fatty acid infusion selectively impairs insulin action on Akt1 and protein kinase $\mathrm{C} \lambda / \zeta$ but not on glycogen synthase kinase-3. Journal of Biological Chemistry 277 32915-32922. (doi:10.1074/jbc.M204710200)

Kim M-Y, Bae Y-J, Bak Y-K, Kim J \& Sung M-K 2012 Effects of highfat diet on intestinal permeability and inflammation-associated tumorigenesis. FASEB Journal 26 376-377. (doi:10.1096/fj.11-190934)

Klein S, Burke LE, Bray GA, Blair S, Allison DB, Pi-Sunyer X, Hong Y \& Eckel RH 2004 Clinical implications of obesity with specific focus on cardiovascular disease. Circulation 110 2952. (doi:10.1161/01. CIR.0000145546.97738.1E)

Kopecky J, Rossmeisl M, Flachs P, Kuda O, Brauner P, Jilkova Z, Stankova B, Tvrzicka E \& Bryhn M 2009 n-3 PUFA: bioavailability and modulation of adipose tissue function: Symposium on 'Frontiers in adipose tissue biology'. Proceedings of the Nutrition Society 68 361-369.

Kubant R, Poon AN, Sanchez-Hernandez D, Domenichiello AF, Huot PSP, Pannia E, Cho CE, Hunschede S, Bazinet RP \& Anderson GH 2015 A comparison of effects of lard and hydrogenated vegetable shortening on the development of high-fat diet-induced obesity in rats. Nutrition \& Diabetes 5 e188. (doi:10.1038/nutd.2015.40)

Lara-Villoslada F, de Haro O, Camuesco D, Comalada M, Velasco J, Zarzuelo A, Xaus J \& Galvez J 2006 Short-chain fructooligosaccharides, in spite of being fermented in the upper part of the large intestine, have anti-inflammatory activity in the TNBS model of colitis. European Journal of Nutrition 45 418-425. (doi:10.1007/s00394-006-0610-2)

Layman DK \& Walker DA 2006 Potential importance of leucine in treatment of obesity and the metabolic syndrome. Journal of Nutrition 136 319S-323S. (doi:10.14341/2071-8713-5240)

Lee S, Bacha F, Hannon T, Kuk JL, Boesch C \& Arslanian S 2012 Effects of aerobic versus resistance exercise without caloric restriction on abdominal fat, intrahepatic lipid, and insulin sensitivity in obese adolescent boys. Diabetes 612787 . (doi:10.2337/db12-0214)

Ley SH, Hamdy O, Mohan V \& Hu FB 2014 Prevention and management of type 2 diabetes: dietary components and nutritional strategies. Lancet 383 1999-2007. (doi:10.1016/S0140-6736(14)60613-9)

Liang H \& Ward WF 2006 PGC-1 $\alpha$ : a key regulator of energy metabolism. Advances in Physiology Education 30 145. (doi:10.1152/ advan.00052.2006)

http://joe.endocrinology-journals.org

DOI: $10.1530 / J O E-16-0580$
C 2017 Society for Endocrinology Printed in Great Britain
Liu Z, Patil IY, Jiang T, Sancheti H, Walsh JP, Stiles BL, Yin F \& Cadenas E 2015 High-fat diet induces hepatic insulin resistance and impairment of synaptic plasticity. PLOS ONE 10 e0128274. (doi:10.1371/journal. pone.0128274)

López-Alarcón M, Perichart-Perera O, Flores-Huerta S, Inda-Icaza P, Rodríguez-Cruz M, Armenta-Álvarez A, Bram-Falcón MT \& Mayorga-Ochoa M 2014 Excessive refined carbohydrates and scarce micronutrients intakes increase inflammatory mediators and insulin resistance in prepubertal and pubertal obese children independently of obesity. Mediators of Inflammation 2014849031. (doi:10.1155/2014/849031)

Lu C-W, Chang H-H, Yang K-C, Kuo C-S, Lee L-T \& Huang K-C 2016 High serum selenium levels are associated with increased risk for diabetes mellitus independent of central obesity and insulin resistance. BMJ Open Diabetes Research \& Care 4 e000253. (doi:10.1136/ bmjdrc-2016-000253)

Lukaski HC BW, Klevay LM, Milne DB \& Sandstead HH. 2001 Interactions among dietary fat, mineral status, and performance of endurance athletes: a case study. International Journal of Sport Nutrition and Exercise Metabolism 11 186-198. (doi:10.1123/ijsnem.11.2.186)

Lumeng CN \& Saltiel AR 2011 Inflammatory links between obesity and metabolic disease. Journal of Clinical Investigation $1212111-2117$. (doi:10.1172/JCI57132)

Luo X, Jia R, Yao Q, Xu Y, Luo Z, Luo X \& Wang N 2016 Docosahexaenoic acid attenuates adipose tissue angiogenesis and insulin resistance in high fat diet-fed middle-aged mice via a sirt1-dependent mechanism. Molecular Nutrition \& Food Research 60 871-885. (doi:10.1002/ mnfr.201500714)

Luong Kvq \& Nguyen LTH 2012 The Impact of Thiamine Treatment in the Diabetes Mellitus. Journal of Clinical Medicine Research 4 153-160. (doi:10.4021/jocmr890w)

Mahendran Y, Jonsson A, Have CT, Allin KH, Witte DR, Jørgensen ME, Grarup N, Pedersen O, Kilpeläinen TO \& Hansen T 2017 Genetic evidence of a causal effect of insulin resistance on branched-chain amino acid levels. Diabetologia 60 873-878. (doi:10.1007/s00125-0174222-6)

Manning PJ, Sutherland WHF, Walker RJ, Williams SM, de Jong SA, Ryalls AR \& Berry EA 2004 Effect of high-dose vitamin E on insulin resistance and associated parameters in overweight subjects. Diabetes Care 27 2166. (doi:10.2337/diacare.27.9.2166)

Mariosa LSS, Ribeiro-Filho FF, Batista MC, Hirota AH, Borges RL, Ribeiro AB \& Zanella MT 2008 Abdominal obesity is associated with potassium depletion and changes in glucose homeostasis during diuretic therapy. Journal of Clinical Hypertension 10 443-449. (doi:10.1111/j.1751-7176.2008.07817.x)

Markovic TP, Jenkins AB, Campbell LV, Furler SM, Kraegen EW \& Chisholm DJ. 1998 The determinants of glycemic responses to diet restriction and weight loss in obesity and NIDDM. Diabetes Care 21 687-694. (doi:10.2337/diacare.21.5.687)

Marques-Vidal P, Vollenweider P, Guessous I, Henry H, Boulat O, Waeber G \& Jornayvaz FR 2015 Serum vitamin D concentrations are not associated with insulin resistance in Swiss adults. Journal of Nutrition 145 2117-2122. (doi:10.3945/jn.115.211763)

Martin CK, Bhapkar M, Pittas AG, Pieper CF, Das SK, Williamson DA, Scott T, Redman LM, Stein R, Gilhooly CH, et al. 2016 Effect of calorie restriction on mood, quality of life, sleep, and sexual function in healthy nonobese adults: the calerie 2 randomized clinical trial. JAMA Internal Medicine 176 743-752. (doi:10.1001/ jamainternmed.2016.1189)

Mashek DG \& Wu C 2015 MUFAs. Advances in Nutrition 6 276-277. (doi:10.3945/an.114.005926)

McKnight JR, Satterfield MC, Jobgen WS, Smith SB, Spencer TE Meininger CJ, McNeal CJ \& Wu G 2010 Beneficial effects of l-arginine on reducing obesity: potential mechanisms and important implications for human health. Amino Acids 39 349-357. (doi:10.1007/s00726-010-0598-z) 
Milanski M, Degasperi G, Coope A, Morari J, Denis R, Cintra DE, Tsukumo DML, Anhe G, Amaral ME, Takahashi HK, et al. 2009 Saturated fatty acids produce an inflammatory response predominantly through the activation of TLR4 signaling in hypothalamus: implications for the pathogenesis of obesity. Journal of Neuroscience 29 359. (doi:10.1523/JNEUROSCI.2760-08.2009)

Mirrahimi A, Chiavaroli L, Srichaikul K, Augustin LSA, Sievenpiper JL, Kendall CWC \& Jenkins DJA 2013 The role of glycemic index and glycemic load in cardiovascular disease and its risk factors: a review of the recent literature. Current Atherosclerosis Reports 16381. (doi:10.1007/s11883-013-0381-1)

Mogensen TH 2009 Pathogen recognition and inflammatory signaling in innate immune defenses. Clinical Microbiology Reviews 22 240-273. (doi:10.1128/CMR.00046-08)

Monk JM, Hou TY, Turk HF, Weeks B, Wu C, McMurray DN \& Chapkin RS 2012 Dietary n-3 polyunsaturated fatty acids (PUFA) decrease obesityassociated Th17 cell-mediated inflammation during colitis. PLoS ONE 7 e49739. (doi:10.1371/journal.pone.0049739)

Morino K, Petersen KF \& Shulman GI 2006 Molecular mechanisms of insulin resistance in humans and their potential links with mitochondrial dysfunction. Diabetes 55 S9-S15. (doi:10.2337/ db06-S002)

Moslehi N, Ehsani B, Mirmiran P, Hojjat P \& Azizi F 2015 Association of dietary proportions of macronutrients with visceral adiposity index: non-substitution and iso-energetic substitution models in a prospective study. Nutrients 7 8859-8870. (doi:10.3390/nu7105436)

Nakano T, Cheng Y-F, Lai C-Y, Hsu L-W, Chang Y-C, Deng J-Y, Huang Y-Z, Honda H, Chen K-D, Wang C-C, et al. 2011 Impact of artificial sunlight therapy on the progress of non-alcoholic fatty liver disease in rats. Journal of Hepatology 55 415-425. (doi:10.1016/j. jhep.2010.11.028)

Nan Y-M, Wu W-J, Fu N, Liang B-L, Wang R-Q, Li L-X, Zhao S-X, Zhao $\mathrm{J}-\mathrm{M} \& \mathrm{Yu} \mathrm{J} 2009$ Antioxidants vitamin $\mathrm{E}$ and 1-aminobenzotriazole prevent experimental non-alcoholic steatohepatitis in mice. Scandinavian Journal of Gastroenterology 44 1121-1131. (doi:10.1080/00365520903114912)

Natarajan N \& Pluznick J 2015 Short chain fatty acid metabolites lower blood pressure via endothelial Gpr41. FASEB Journal 29 (Supplement 1) 811.5. (available at: http://www.fasebj.org/ content/29/1_Supplement/811.5.short)

Neels JG \& Olefsky JM 2006 Inflamed fat: what starts the fire? Journal of Clinical Investigation 116 33-35. (doi:10.1172/JCI27280)

Neuschwander-Tetri BA 2013 Carbohydrate intake and nonalcoholic fatty liver disease. Current Opinion in Clinical Nutrition \& Metabolic Care 16 446-452.

Nikoulina SE, Ciaraldi TP, Carter L, Mudaliar S, Park KS \& Henry RR 2001 Impaired muscle glycogen synthase in type 2 diabetes is associated with diminished phosphatidylinositol 3-Kinase activation. Journal of Clinical Endocrinology \& Metabolism 86 4307-4314. (doi:10.1210/ jc.86.9.4307)

Norris LE, Collene AL, Asp ML, Hsu JC, Liu L-F, Richardson JR, Li D, Bell D, Osei K, Jackson RD, et al. 2009 Comparison of dietary conjugated linoleic acid with safflower oil on body composition in obese postmenopausal women with type 2 diabetes mellitus. American Journal of Clinical Nutrition 90 468-476. (doi:10.3945/ajcn.2008.27371)

Nseir W, Hellou E \& Assy N 2014 Role of diet and lifestyle changes in nonalcoholic fatty liver disease. World Journal of Gastroenterology: WJG 20 9338-9344.

Oh DY, Talukdar S, Bae EJ, Imamura T, Morinaga H, Fan W, Li P, Lu WJ, Watkins SM \& Olefsky JM 2010 GPR120 is an omega-3 fatty acid receptor mediating potent anti-inflammatory and insulin sensitizing effects. Cell 142 687-698. (doi:10.1016/j.cell.2010.07.041)

Ouchi N, Higuchi A, Ohashi K, Oshima Y, Gokce N, Shibata R, Akasaki Y, Shimono A \& Walsh K 2010 Sfrp5 Is an anti-inflammatory adipokine that modulates metabolic dysfunction in obesity. Science $\mathbf{3 2 9}$ 454-457. (doi:10.1126/science.1188280)
Ouellet V, Marois J, Weisnagel SJ \& Jacques H 2007 Dietary Cod Protein improves insulin sensitivity in insulin-resistant men and women. Diabetes Care 30 2816. (doi:10.2337/dc07-0273)

Paniagua JA, de la Sacristana AG, Romero I, Vidal-Puig A, Latre JM, Sanchez E, Perez-Martinez P, Lopez-Miranda J \& Perez-Jimenez F 2007 Monounsaturated fat-rich diet prevents central body fat distribution and decreases postprandial adiponectin expression induced by a carbohydrate-rich diet in insulin-resistant subjects. Diabetes Care 30 1717. (doi:10.2337/dc06-2220)

Papamiltiadous ES, Roberts SK, Nicoll AJ, Ryan MC, Itsiopoulos C, Salim A \& Tierney AC 2016 A randomised controlled trial of a Mediterranean dietary intervention for adults with non alcoholic fatty liver disease (MEDINA): study protocol. BMC Gastroenterology 16 14. (doi:10.1186/s12876-016-0426-3)

Park S, Park N-Y, Valacchi G \& Lim Y 2012 Calorie restriction with a highfat diet effectively attenuated inflammatory response and oxidative stress-related markers in obese tissues of the high diet fed rats. Mediators of Inflammation 2012 11. (doi:10.1155/2012/352807)

Park D-Y, Ahn Y-T, Park S-H, Huh C-S, Yoo S-R, Yu R, Sung M-K, McGregor RA \& Choi M-S 2013 Supplementation of lactobacillus curvatus HY7601 and lactobacillus plantarum KY1032 in diet-induced obese mice is associated with gut microbial changes and reduction in obesity. PLOS ONE 8 e59470. (doi:10.1371/journal.pone.0059470)

Patrice DC \& Nathalie MD 2009 The role of the gut microbiota in energy metabolism and metabolic disease. Current Pharmaceutical Design 15 1546-1558. (doi:10.2174/138161209788168164)

Picard F, Kurtev M, Chung N, Topark-Ngarm A, Senawong T, Machado de Oliveira R, Leid M, McBurney MW \& Guarente L 2004 Sirt1 promotes fat mobilization in white adipocytes by repressing PPAR-[gamma]. Nature 429 771-776. (doi:10.1038/nature02583)

Racine NM, Watras AC, Carrel AL, Allen DB, McVean JJ, Clark RR, O'Brien AR, O'Shea M, Scott CE \& Schoeller DA 2010 Effect of conjugated linoleic acid on body fat accretion in overweight or obese children. American Journal of Clinical Nutrition 91 1157-1164. (doi:10.3945/ ajcn.2009.28404)

Ridaura VK, Faith JJ, Rey FE, Cheng J, Duncan AE, Kau AL, Griffin NW, Lombard V, Henrissat B, Bain JR, et al. 2013 Cultured gut microbiota from twins discordant for obesity modulate adiposity and metabolic phenotypes in mice. Science 341 10.1126/science.1241214.

Rivellese AA, De Natale C \& Lilli S 2002 Type of dietary fat and insulin resistance. Annals of the New York Academy of Sciences 967 329-335. (doi:10.1111/j.1749-6632.2002.tb04288.x)

Roberts CK, Won D, Pruthi S, Kurtovic S, Sindhu RK, Vaziri ND \& Barnard RJ 2006 Effect of a short-term diet and exercise intervention on oxidative stress, inflammation, MMP-9, and monocyte chemotactic activity in men with metabolic syndrome factors. Journal of Applied Physiology 100 1657. (doi:10.1152/japplphysiol.01292.2005)

Rodríguez-Moran M \& Guerrero-Romero F 2014 Oral magnesium supplementation improves the metabolic profile of metabolically obese, normal-weight individuals: a randomized double-blind placebo-controlled trial. Archives of Medical Research 45 388-393. (doi:10.1016/j.arcmed.2014.05.003)

Roseno SL, Davis PR, Bollinger LM, Powell JJS, Witczak CA \& Brault JJ 2015 Short-term, high-fat diet accelerates disuse atrophy and protein degradation in a muscle-specific manner in mice. Nutrition \& Metabolism 12 39. (doi:10.1186/s12986-015-0037-y)

Roth CL, Elfers CT, Figlewicz DP, Melhorn SJ, Morton GJ, Hoofnagle A, Yeh MM, Nelson JE \& Kowdley KV 2012 Vitamin D deficiency in obese rats exacerbates nonalcoholic fatty liver disease and increases hepatic resistin and toll-like receptor activation. Hepatology $\mathbf{5 5}$ 1103-1111. (doi:10.1002/hep.24737)

Sáez-Lara M, Robles-Sanchez C, Ruiz-Ojeda F, Plaza-Diaz J \& Gil A 2016 Effects of probiotics and synbiotics on obesity, insulin resistance syndrome, type 2 diabetes and non-alcoholic fatty liver disease: a review of human clinical trials. International Journal of Molecular Sciences 17 928. (doi:10.3390/ijms17060928) 
Sailer M, Dahlhoff C, Giesbertz P, Eidens MK, de Wit N, Rubio-Aliaga I, Boekschoten MV, Müller M \& Daniel H 2013 Increased Plasma Citrulline in mice marks diet-induced obesity and may predict the development of the metabolic syndrome. PLOS ONE 8 e63950. (doi:10.1371/journal.pone.0063950)

Saito M 2013 Brown adipose tissue as a regulator of energy expenditure and body fat in humans. Diabetes \& Metabolism Journal 37 22-29. (doi:10.4093/dmj.2013.37.1.22)

Sampey BP, Vanhoose AM, Winfield HM, Freemerman AJ, Muehlbauer MJ, Fueger PT, Newgard CB \& Makowski L 2011 Cafeteria diet is a robust model of human metabolic syndrome with liver and adipose inflammation: comparison to high-fat diet. Obesity 19 1109-1117. (doi:10.1038/oby.2011.18)

Samuel BS, Shaito A, Motoike T, Rey FE, Backhed F, Manchester JK, Hammer RE, Williams SC, Crowley J, Yanagisawa M, et al. 2008 Effects of the gut microbiota on host adiposity are modulated by the shortchain fatty-acid binding $\mathrm{G}$ protein-coupled receptor, Gpr41. PNAS 105 16767-16772. (doi:10.1073/pnas.0808567105)

Santamarina AB, Oliveira JL, Silva FP, Carnier J, Mennitti LV, Santana AA, de Souza GHI, Ribeiro EB, Oller do Nascimento CM, Lira FS, et al. 2015 Green tea extract rich in epigallocatechin-3-gallate prevents fatty liver by AMPK activation via LKB1 in mice fed a high-fat diet. PLOS ONE 10 e0141227. (doi:10.1371/journal.pone.0141227)

Sartipy P \& Loskutoff DJ 2003 Monocyte chemoattractant protein 1 in obesity and insulin resistance. PNAS 100 7265-7270. (doi:10.1073/ pnas.1133870100)

Saxena M \& Yeretssian G 2014 NOD-like receptors: master regulators of inflammation and cancer. Frontiers in Immunology 5 327. (doi:10.3389/ fimmu.2014.00327)

Schwab JM \& Serhan CN 2006 Lipoxins and new lipid mediators in the resolution of inflammation. Current Opinion in Pharmacology 6 414-420. (doi:10.1016/j.coph.2006.02.006)

Semrin G, Fishman DS, Bousvaros A, Zholudev A, Saunders AC, Correia CE, Nemeth E, Grand RJ \& Weinstein DA 2006 Impaired intestinal iron absorption in crohn's disease correlates with disease activity and markers of inflammation. Inflammatory Bowel Diseases 12 1101-1106. (doi:10.1097/01.mib.0000235097.86360.04)

Senthil Kumar SPD, Shen M, Spicer EG, Goudjo-Ako AJ, Stumph JD, Zhang J \& Shi H 2014 Distinct metabolic effects following shortterm exposure of different high-fat diets in male and female mice. Endocrine Journal 61 457-470. (doi:10.1507/endocrj.EJ13-0455)

Seo K-H, Kim H, Chon J-W, Kim D-H, Nah S-Y, Arvik T \& Yokoyama W 2015 Flavonoid-rich Chardonnay grape seed flour supplementation ameliorates diet-induced visceral adiposity, insulin resistance, and glucose intolerance via altered adipose tissue gene expression. Journal of Functional Foods 17 881-891. (doi:10.1016/j. jff.2015.06.039)

Shimabukuro M, Higa M, Zhou Y-T, Wang M-Y, Newgard CB \& Unger RH 1998 Lipoapoptosis in beta-cells of obese prediabeticfa/ fa rats: role of serine palmitoyltransferase overexpression. Journal of Biological Chemistry 273 32487-32490. (doi:10.1074/ jbc.273.49.32487)

Shirpoor A, Ansari MHK, Salami S, Pakdel FG \& Rasmi Y 2007 Effect of vitamin $\mathrm{E}$ on oxidative stress status in small intestine of diabetic rat. World Journal of Gastroenterology 13 4340-4344. (doi:10.3748/wjg.v13. i32.4340)

Sieri S, Krogh V, Agnoli C, Ricceri F, Palli D, Masala G, Panico S, Mattiello A, Tumino R, Giurdanella MC, et al. 2015 Dietary glycemic index and glycemic load and risk of colorectal cancer: results from the EPIC-Italy study. International Journal of Cancer 136 2923-2931. (doi:10.1002/ ijc.29341)

Sonnweber T, Ress C, Nairz M, Theurl I, Schroll A, Murphy AT, Wroblewski V, Witcher DR, Moser P, Ebenbichler CF, et al. 2012 Highfat diet causes iron deficiency via hepcidin-independent reduction of duodenal iron absorption. Journal of Nutritional Biochemistry 23 1600-1608. (doi:10.1016/j.jnutbio.2011.10.013)
Souza CO, Teixeira AAS, Lima EA, Batatinha HAP, Gomes LM, CarvalhoSilva M, Mota IT, Streck EL, Hirabara SM, Neto J, et al. 2014 Palmitoleic acid (N-7) attenuates the immunometabolic disturbances caused by a high-fat diet independently of PPAR $\alpha$. Mediators of Inflammation 2014 12. (doi:10.1155/2014/582197)

Sparks LM, Redman LM, Conley KE, Harper M-E, Yi F, Hodges A, Eroshkin A, Costford SR, Gabriel ME, Shook C, et al. 2017 Effects of 12 months of caloric restriction on muscle mitochondrial function in healthy individuals. Journal of Clinical Endocrinology \& Metabolism 102 111-121. (doi:10.1210/jc.2016-3211)

Speakman JR 2004 Obesity: The integrated roles of environment and genetics. Journal of Nutrition 134 2090S-2105S.

Spencer M, Finlin BS, Unal R, Zhu B, Morris AJ, Shipp LR, Lee J, Walton RG, Adu A, Erfani R, et al. 2013 Omega-3 fatty acids reduce adipose tissue macrophages in human subjects with insulin resistance. Diabetes 62 1709-1717. (doi:10.2337/db12-1042)

Suez J, Korem T, Zeevi D, Zilberman-Schapira G, Thaiss CA, Maza O, Israeli D, Zmora N, Gilad S, Weinberger A, et al. 2014 Artificial sweeteners induce glucose intolerance by altering the gut microbiota. Nature 514 181-186. (doi:10.1038/nature13793)

Sukhotnik I, Mor-Vaknin N, Drongowski RA, Miselevich I, Coran AG \& Harmon CM 2004 Effect of dietary fat on early morphological intestinal adaptation in a rat with short bowel syndrome. Pediatric Surgery International 20 419-424. (doi:10.1007/s00383-004-1168-9)

Suliburska J, Cofta S, Gajewska E, Kalmus G, Sobieska M, Samborski W, Krejpcio Z, Drzymala-Czyz S \& Bogdanski P 2013 The evaluation of selected serum mineral concentrations and their association with insulin resistance in obese adolescents. European Review for Medical and Pharmacological Sciences 17 2396-2400

Sung C-C, Liao M-T, Lu K-C \& Wu C-C 2012 Role of Vitamin D in insulin resistance. Journal of Biomedicine and Biotechnology 201211.

Szallasi A, Blumberg PM, Annicelli LL, Krause JE \& Cortright DN 1999 The cloned rat Vanilloid Receptor VR1 mediates both R-type binding and C-type calcium response in dorsal root ganglion neurons. Molecular Pharmacology 56581.

Takatsu M, Nakashima C, Takahashi K, Murase T, Hattori T, Ito H, Murohara T \& Nagata K 2013 Calorie restriction attenuates cardiac remodeling and diastolic dysfunction in a rat model of metabolic syndrome. Hypertension 62 957. (doi:10.1161/ HYPERTENSIONAHA.113.02093)

Talaei A, Mohamadi M \& Adgi Z 2013 The effect of vitamin D on insulin resistance in patients with type 2 diabetes. Diabetology \& Metabolic Syndrome 5 8-8. (doi:10.1186/1758-5996-5-8)

Tang Y, Purkayastha S \& Cai D 2015 Hypothalamic micro-inflammation: a common basis of metabolic syndrome and aging. Trends in neurosciences 38 36-44. (doi:10.1016/j.tins.2014.10.002)

Tchernof A \& Després J-P 2013 Pathophysiology of human visceral obesity: an update. Physiological Reviews 93 359. (doi:10.1152/ physrev.00033.2011)

Teng K-T, Chang C-Y, Chang LF \& Nesaretnam K 2014 Modulation of obesity-induced inflammation by dietary fats: mechanisms and clinical evidence. Nutrition Journal 13 12-12. (doi:10.1186/1475-2891-13-12)

Terzić J, Grivennikov S, Karin E \& Karin M 2010 Inflammation and colon cancer. Gastroenterology 138 2101-2114.e2105.

Todoric J, Löffler M, Huber J, Bilban M, Reimers M, Kadl A, Zeyda M, Waldhäusl W \& Stulnig TM 2006 Adipose tissue inflammation induced by high-fat diet in obese diabetic mice is prevented by $\mathrm{n}-3$ polyunsaturated fatty acids. Diabetologia 49 2109-2119. (doi:10.1007/ s00125-006-0300-x)

Tomada I, Fernandes D, Guimarães JT, Almeida H \& Neves D 2013 Energy restriction ameliorates metabolic syndrome-induced cavernous tissue structural modifications in aged rats. AGE 35 1721-1739. (doi:10.1007/s11357-012-9473-z)

Toral M, Gómez-Guzmán M, Jiménez R, Romero M, Sánchez M, Utrilla María P, Garrido-Mesa N, Rodríguez-Cabezas María E, Olivares M, Gálvez J, et al. 2014 The probiotic Lactobacillus coryniformis CECT5711 
reduces the vascular pro-oxidant and pro-inflammatory status in obese mice. Clinical Science 127 33. (doi:10.1042/CS20130339)

Turati F, Dilis V, Rossi M, Lagiou P, Benetou V, Katsoulis M, Naska A, Trichopoulos D, La Vecchia C \& Trichopoulou A 2014 Glycemic load and coronary heart disease in a Mediterranean population: the EPIC Greek cohort study. Nutrition, Metabolism and Cardiovascular Diseases 25 336-342. (doi:10.1016/j.numecd.2014.12.002)

Turnbaugh PJ, Ley RE, Mahowald MA, Magrini V, Mardis ER \& Gordon JI 2006 An obesity-associated gut microbiome with increased capacity for energy harvest. Nature $\mathbf{4 4 4}$ 1027-1131. (doi:10.1038/ nature05414)

Turnbaugh PJ, Backhed F, Fulton L \& Gordon JI 2008 Marked alterations in the distal gut microbiome linked to diet-induced obesity. Cell host \& microbe 3 213-223.

Turnbaugh PJ \& Gordon JI 2009 The core gut microbiome, energy balance and obesity. Journal of Physiology $\mathbf{5 8 7}$ 4153-4158. (doi:10.1113/ jphysiol.2009.174136)

van Dijk SJ, Feskens EJ, Bos MB, Hoelen DW, Heijligenberg R, Bromhaar MG, de Groot LC, de Vries JH, Müller M \& Afman LA 2009 A saturated fatty acid-rich diet induces an obesity-linked proinflammatory gene expression profile in adipose tissue of subjects at risk of metabolic syndrome. American Journal of Clinical Nutrition 90 1656-1664. (doi:10.3945/ajcn.2009.27792)

Vezza T, Rodríguez-Nogales A, Algieri F, Utrilla MP, Rodriguez-Cabezas ME \& Galvez J 2016 Flavonoids in inflammatory bowel disease: a review. Nutrients 8 211. (doi:10.3390/nu8040211)

Via MA \& Mechanick JI 2016 Nutrition in type 2 diabetes and the metabolic syndrome. Medical Clinics of North America 100 1285-1302. (doi:10.1016/j.mcna.2016.06.009)

Vissers D, Hens W, Taeymans J, Baeyens J-P, Poortmans J \& Van Gaal L 2013 The effect of exercise on visceral adipose tissue in overweight adults: a systematic review and meta-analysis. PLOS ONE 8 e56415. (doi:10.1371/journal.pone.0056415)

Wang CCL, Adochio RL, Leitner JW, Abeyta IM, Draznin B \& Cornier M-A 2012 Acute effects of different diet compositions on skeletal muscle insulin signalling in obese individuals during caloric restriction. Metabolism - Clinical and Experimental 62 595-603. (doi:10.1016/j. metabol.2012.10.010)

Wang N, Wang H, Yao HUA, Wei QIN, Mao X-M, Jiang TAO, Xiang J \& Dila NA 2013 Expression and activity of the TLR4/NF-кB signaling pathway in mouse intestine following administration of a shortterm high-fat diet. Experimental and Therapeutic Medicine 6 635-640. (doi:10.3892/etm.2013.1214)

Wang X, Ota N, Manzanillo P, Kates L, Zavala-Solorio J, Eidenschenk C, Zhang J, Lesch J, Lee WP, Ross J, et al. 2014 Interleukin-22 alleviates metabolic disorders and restores mucosal immunity in diabetes. Nature 514 237-241. (doi:10.1038/nature13564)

Wang J, Tang H, Zhang C, Zhao Y, Derrien M, Rocher E, van-Hylckama Vlieg JET, Strissel K, Zhao L, Obin M, et al. 2015a Modulation of gut microbiota during probiotic-mediated attenuation of metabolic syndrome in high fat diet-fed mice. ISME Journal 9 1-15. (doi:10.1038/ismej.2014.99)

Wang X, You T, Murphy K, Lyles MF \& Nicklas BJ 2015b Addition of exercise increases plasma adiponectin and release from adipose tissue. Medicine and Science in Sports and Exercise 47 2450-2455. (doi:10.1249/ MSS.0000000000000670)

Warren HS, Fitting C, Hoff E, Adib-Conquy M, Beasley-Topliffe L, Tesini B, Liang X, Valentine C, Hellman J, Hayden D, et al. 2010 Resilience to bacterial infection: difference between species could be due to proteins in serum. Journal of Infectious Diseases 201 223-232. (doi:10.1086/649557)

Wasinski F, Bacurau RFP, Moraes MR, Haro AS, Moraes-Vieira PMM, Estrela GR, Paredes-Gamero EJ, Barros CC, Almeida SS, et al. 2013 Exercise and caloric restriction alter the immune system of mice submitted to a high-fat diet. Mediators of Inflammation 20138. (doi:10.1155/2013/395672)
Weisburger JH 1997 Tea and health: a historical perspective. Cancer Letters 114 315-317. (doi:10.1016/S0304-3835(97)04691-0)

Wellen KE \& Hotamisligil GS 2003 Obesity-induced inflammatory changes in adipose tissue. Journal of Clinical Investigation $\mathbf{1 1 2}$ 1785-1788. (doi:10.1172/JCI20514)

White MF 2003 Insulin signaling in health and disease. Science 3021710. (doi:10.1126/science.1092952)

White PJ, Lapworth AL, An J, Wang L, McGarrah RW, Stevens RD, Ilkayeva O, George T, Muehlbauer MJ, Bain JR, et al. 2016 Branchedchain amino acid restriction in Zucker-fatty rats improves muscle insulin sensitivity by enhancing efficiency of fatty acid oxidation and acyl-glycine export. Molecular Metabolism 5 538-551. (doi:10.1016/j. molmet.2016.04.006)

Wilson PF, D'Agostino RB, Sullivan L, Parise H \& Kannel WB 2002 Overweight and obesity as determinants of cardiovascular risk: the framingham experience. Archives of Internal Medicine 162 1867-1872. (doi:10.1001/archinte.162.16.1867)

Wing RR BE, Bononi P, Marcus MD, Watanabe R \& Bergman RN. 1994 Caloric restriction per se is a significant factor in improvements in glycemic control and insulin sensitivity during weight loss in obese NIDDM patients. Diabetes Care 17 30-36. (doi:10.2337/diacare.17.1.30)

Woo S-L, Xu H, Li H, Zhao Y, Hu X, Zhao J, Guo X, Guo T, Botchlett R, Qi T, et al. 2014 Metformin ameliorates hepatic steatosis and inflammation without altering adipose phenotype in diet-induced obesity. PLOS ONE 9 e91111. (doi:10.1371/journal.pone.0091111)

Woodside JV, McCall D, McGartland C \& Young IS 2005 Micronutrients: dietary intake v. supplement use. Proceedings of the Nutrition Society 64 543-553. (doi:10.1079/PNS2005464)

Xu H, Barnes GT, Yang Q, Tan G, Yang D, Chou CJ, Sole J, Nichols A, Ross JS, Tartaglia LA, et al. 2003 Chronic inflammation in fat plays a crucial role in the development of obesity-related insulin resistance. Journal of Clinical Investigation 112 1821-1830. (doi:10.1172/ JCI200319451)

Yagi H, Tan J \& Tuan RS 2013 Polyphenols suppress hydrogen peroxide-induced oxidative stress in human bone-marrow derived mesenchymal stem cells. Journal of Cellular Biochemistry 1141163 1173. (doi:10.1002/jcb.24459)

Yang Y, Duan W, Liang Z, Yi W, Yan J, Wang N, Li Y, Chen W, Yu S, Jin $Z$, et al. 2013 Curcumin attenuates endothelial cell oxidative stress injury through Notch signaling inhibition. Cellular Signalling 25 615-629. (doi:10.1016/j.cellsig.2012.11.025)

Ye J \& Keller JN 2010 Regulation of energy metabolism by inflammation: a feedback response in obesity and calorie restriction. Aging $\mathbf{2}$ 361-368. (doi:10.18632/aging.100155)

Yen C-LE, Nelson DW \& Yen M-I 2015 Intestinal triacylglycerol synthesis in fat absorption and systemic energy metabolism. Journal of Lipid Research 56 489-501. (doi:10.1194/jlr.R052902)

Yoneshiro T, Aita S, Kawai Y, Iwanaga T \& Saito M 2012 Nonpungent capsaicin analogs (capsinoids) increase energy expenditure through the activation of brown adipose tissue in humans. American Journal of Clinical Nutrition 95 845-850. (doi:10.3945/ajcn.111.018606)

Yoneshiro T, Aita S, Matsushita M, Kayahara T, Kameya T, Kawai Y, Iwanaga T \& Saito M 2013 Recruited brown adipose tissue as an antiobesity agent in humans. Journal of Clinical Investigation $\mathbf{1 2 3}$ 3404-3408. (doi:10.1172/JCI67803)

Zaakouk AM, Hassan MA \& Tolba OA 2016 Serum magnesium status among obese children and adolescents. Egyptian Pediatric Association Gazette 64 32-37. (doi:10.1016/j.epag.2015.11.002)

Zampieri TT, Torres-Leal FL, Campaña AB, Lima FB \& Donato J 2014 1-Leucine supplementation worsens the adiposity of already obese rats by promoting a hypothalamic pattern of gene expression that favors fat accumulation. Nutrients 6 1364-1373. (doi:10.3390/nu6041364)

Zhang Y, Guo K, LeBlanc RE, Loh D, Schwartz GJ \& Yu Y-H 2007 Increasing dietary leucine intake reduces diet-induced obesity and improves glucose and cholesterol metabolism in mice via multimechanisms. Diabetes 56 1647. (doi:10.2337/db07-0123) 
Zhang X, Zhang G, Zhang H, Karin M, Bai H \& Cai D 2008 Hypothalamic IKK $\beta / \mathrm{NF}-\kappa \mathrm{B}$ and ER stress link overnutrition to energy imbalance and obesity. Cell 135 61-73. (doi:10.1016/j. cell.2008.07.043)

Zhenyukh O, Civantos E, Ruiz-Ortega M, Sánchez MS, Vázquez C, Peiró C, Egido J \& Mas S 2017 High concentration of branchedchain amino acids promotes oxidative stress, inflammation and migration of human peripheral blood mononuclear cells via mTORC1 activation. Free Radical Biology and Medicine 104 165-177. (doi:10.1016/j.freeradbiomed.2017.01.009)

Zierath JR, Houseknecht KL, Gnudi L \& Kahn BB 1997 High-fat feeding impairs insulin-stimulated GLUT4 recruitment via an early insulin-signaling defect. Diabetes 46 215. (doi:10.2337/ diab.46.2.215)

Zimmermann E, Anty R, Tordjman J, Verrijken A, Gual P, Tran A, Iannelli A, Gugenheim J, Bedossa P, Francque S, et al. 2011 C-reactive protein levels in relation to various features of non-alcoholic fatty liver disease among obese patients. Journal of Hepatology 55 660-665. (doi:10.1016/j.jhep.2010.12.017)

Zúñiga J, Cancino M, Medina F, Varela P, Vargas R, Tapia G, Videla LA \& Fernández V 2011 N-3 PUFA supplementation triggers PPAR- $\alpha$ activation and PPAR- $\alpha / \mathrm{NF}-\kappa \mathrm{B}$ interaction: anti-inflammatory implications in liver ischemia-reperfusion injury. PLOS ONE 6 e28502. (doi:10.1371/journal.pone.0028502)

Received in final form 15 March 2017

Accepted 11 April 2017

Accepted Preprint published online 11 April 2017
Published by Bioscientifica Ltd. 